\title{
Microbial Efficacy and Two Step Synthesis of Uridine Derivatives with Spectral Characterization
}

\author{
Sumi R. Devi', Sanjida Jesmin ${ }^{1}$, Mahfuz Rahman¹, Mohammad A. Manchur², Yuki \\ Fujii $^{3}$, Yasuhiro Ozeki ${ }^{4}$, Sarkar M. A. Kawsar ${ }^{*}$ \\ 1 Laboratory of Carbohydrate and Nucleoside Chemistry, Department of Chemistry, Faculty of Science, University of Chit- \\ tagong, Chittagong 4331, Bangladesh. \\ 2 Department of Microbiology, Faculty of Biological Science, University of Chittagong, Chittagong-4331, Bangladesh \\ 3Department of Pharmacy, Faculty of Pharmaceutical Science, Nagasaki International University, 2825-7 Huis Ten Bosch, \\ Sasebo, Nagasaki 859-3298, Japan \\ 4 Department of Life and Environmental System Science, Graduate School of NanoBio Sciences, Yokohama City Univer- \\ sity, 22-2 Seto, Kanazawa-ku, Yokohama 236-0027, Japan
}

\begin{abstract}
Uridine is a natural nucleoside precursor of uridine monophosphate in organisms and thus is considered to be safe and is used in a wide range of clinical settings. The farreaching effects of pharmacological uridine have long been neglected. Here, we report a novel series of uridine esters were designed and synthesized by direct method with microbial efficacy. The structures of the prepared compounds have been characterized using various physico-chemical methods including $\mathrm{C}, \mathrm{H}$ elemental analysis, melting point determination, IR and ${ }^{1} \mathrm{H}-\mathrm{NMR}$ spectroscopy. The synthesized uridine derivatives were subjected to in-vitro antibacterial screening using agar disc diffusion method on some clinically isolated Gram-positive and Gram-negative bacterial strains. Also, antifungal functionality test was performed against a number of plant pathogenic fungi. The compounds showed varied antibacterial and antifungal activities. In addition, cytotoxic activity showed different rate mortality with different concentrations. In conclusion, it may useful for antibacterial and antifungal active agents after investigating their further analysis to develop safer and more potent drugs in the future.
\end{abstract}

Keywords: Synthesis, uridine, structure, efficacy, pathogens

\section{INTRODUCTION}

Uridine (1) is one of the four basic components of robonucleic acid (RNA). Upon digestion of foods containing RNA, uridine is released from RNA and is absorbed intact in the gut. Uridine is found in sugarcane, tomatos, broccoli, liver,

*Corresponding author: Sarkar M. A. Kawsar, e-mail: akawsarabe@yahoo.com (Received 06 October 2018, accepted 20 October 2018) 
pancreas etc. Uridine has anti depression activity, asthmatic airway inflammation, hepatocyte proliferation ${ }^{1,2}$. In addition, uridine has been reported to have other physiological actions in animal studies, such as a vasoconstrictive effect in rats, which was reversed by adenosine ${ }^{3}$ and hyperpolarized amphibian ganglia and superior cervical ganglia in rats, possibly related to an inhibitory activity4. In humans, uridine is administered to reduce the adverse effects of cancer chemotherapy including 5 -fluorouracil, such as bone marrow and gastrointestinal toxicity 5 . Furthermore, a combination of uridine and benzylacyclouridine (uridine phosphorylase inhibitor) was shown to reduce neurotoxicity and bone marrow toxicity related to zidovudine used for treatment of HIV infection ${ }^{6}$. However, the physiological activities of uridine in humans remain undetermined.

Nucleotides and nucleosides are key compounds involved in major biological processes, such as nucleic acids and proteins synthesis, cell signaling, enzyme regulation, and metabolism. Indeed, many nucleoside analogues are already clinically used as antiviral ${ }^{7,8}$ and antitumoral agents ${ }^{9,10}$. However, their efficiency is sometimes reduced by the appearance of resistance mechanisms ${ }^{11}$. The availability of new nucleoside derivatives ${ }^{12}$, therefore, is still of prime importance.

A number of fruitful and efficient methods for selective acylation were reported by many carbohydrate chemists using many acylating agents and varying reaction conditions ${ }^{13,14}$. However, most of these methods are based on the blocking and deblocking of the hydroxyl groups which are not directly involved in the reaction ${ }^{15,16}$. Various methods for acylation of carbohydrates and nucleosides have so far been developed and employed successfully ${ }^{17-19}$. Of these, direct method has been found to be the most encouraging method for acylation of carbohydrates and nucleosides ${ }^{20}$.

From literature survey revealed that a large number of biologically active compounds possess aromatic and heteroaromatic nucleus and acyl substituents $^{21,22}$. It is also known that, if an active nucleus is linked to another nucleus, the resulting molecule may possess greater potential for biological activity ${ }^{23}$. The benzene and substituted benzene nuclei play important role as common denominator of various biological activities ${ }^{24}$. Results of an ongoing research work on selective acylation of nucleosides ${ }^{25}$ and also evaluation of antimicrobial activities reveal that in many cases the combination of two or more aromatic or heteroaromatic nuclei ${ }^{23}$. It is also found that $\mathrm{N}, \mathrm{S}$ and $\mathrm{X}$ containing substitution products showed marked antimicrobial activities i.e., enhance the biological activity of the parent compound ${ }^{26,27}$. Encouraged by literature reports and our own findings ${ }^{28,29}$, we synthesized some selectively acylated derivatives of 
uridine (1) (Scheme 1- 2 \& Table 1) containing various substituents in a single molecular framework and evaluated their antibacterial and antifungal activities using a variety of bacterial and fungal pathogens.

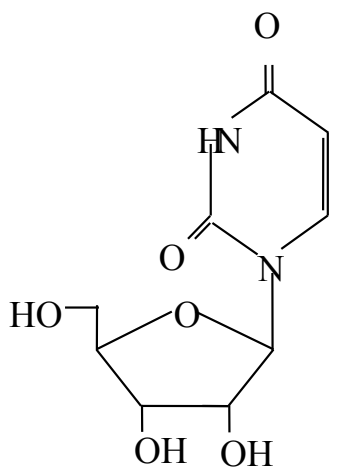

Figure 1. Uridine (Compound 1)

\section{METHODOLOGY}

\section{Chemicals}

Melting points were determined on an electro-thermal melting point apparatus (England) and are uncorrected. Evaporations were carried out under reduced pressure using VV-1 type vacuum rotary evaporator (Germany) with a bath temperature below $40^{\circ} \mathrm{C}$. Thin layer chromatography (t.l.c) was performed on Kieselgel $\mathrm{GF}_{254}$ and spots were detected by spraying the plates with $1 \% \mathrm{H}_{2} \mathrm{SO}_{4}$ and heating at $150-200^{\circ} \mathrm{C}$ until coloration took place. Column chromatography was performed with silica gel $\mathrm{G}_{60}$. All reagents used were commercially available (Aldrich) and were used as received, unless otherwise specified.

\section{Structure and physical properties of uridine derivatives}

The structures of newly synthesized compounds were determined through NMR spectroscopy and mass spectrometry. ${ }^{1} \mathrm{H}-\mathrm{NMR}$ spectra $(40 \mathrm{OHHz})$ were recorded for solutions in deuteriochloroform $\left(\mathrm{CDCl}_{3}\right)$ (internal $\mathrm{Me}_{4} \mathrm{Si}$ ) with a Bruker DPX-40C spectrometer. Synthesized compounds were also conducted by liquid chromatography electrospray ionization-tandem mass spectrometry in positive ionization mode (LC/ESI(+)-MS/MS) by using a system that consisted of a JASSO LC (JASCO, Tokyo, Japan) at the Yokohama City University, Japan. IR spectra were recorded by KBr disc at the Chemistry Department, University of Chittagong, Bangladesh, with an IR Affinity Fourier Transform Infrared Spectrophotometer (SHIMADZU). The physical properties were de- 
termined and characterized by melting point and elemental analysis ( $\mathrm{C}$ and $\mathrm{H}$ ).

\section{Synthesis of uridine derivatives}

\section{$5^{\prime}$-O-octanoyluridine (Compound 2)}

A solution of the uridine (1) (200 $\mathrm{mg}, 0.83 \mathrm{mmol}$ ) in anhydrous pyridine (3 ml) was cooled to $\mathrm{O}^{\circ} \mathrm{C}$ when octanoyl chloride (0.3 ml, 1.1 molar eq.) was added. The reaction mixture was continuously stirred for 6 hours at $\mathrm{o}^{\circ} \mathrm{C}$ temperature and then the reaction mixture was standing for overnight at room temperature with continuous stirring. The progress of the reaction was monitored by t.l.c (methanol-chloroform, 1:24) which indicated full conversion of the starting material into a single product $\left(R_{f}=0.50\right)$. The solution was poured into ice water with constant stirring. It was then extracted with chloroform $(3 \times 10 \mathrm{ml})$. The combined chloroform layer was washed successively with dilute hydrochloric acid, saturated aqueous sodium hydrogen carbonate solution and distilled water. The organic layer was dried $\left(\mathrm{Na}_{2} \mathrm{SO}_{4}\right)$, filtered and concentrated. The organic layer was dried $\left(\mathrm{MgSO}_{4}\right)$, filtered and concentrated. Purification by chromatography with methanol-chloroform (1:24) as eluant and furnished the octanoyl chloride derivative (2) (164 mg, 82\%) as solid mass, which was used in the next stage. Physical properties are shown in the Table 2.

Colour: white, solubility: $\mathrm{CHCl}_{3}$, DMF. FTIR $(\mathrm{KBr}) \mathrm{v}_{\max }\left(\mathrm{cm}^{-1}\right) 1728(\mathrm{C}=\mathrm{O})$, 3358-3520 (br, -OH). ${ }^{1} \mathrm{H}-\mathrm{NMR}\left(400 \mathrm{MHz} \mathrm{CDCl}_{3}\right): \delta_{\mathrm{H}} 9.08(1 \mathrm{H}, \mathrm{s},-\mathrm{NH}), 7.53$ $(1 \mathrm{H}, \mathrm{d}, \mathrm{J}=7.8 \mathrm{~Hz}, \mathrm{H}-6), 5.98$ (1H, d, J=5.6 Hz, H-1' ), 5.88 (1H, s, 2' $-\mathrm{OH}), 5.81$ $\left(1 \mathrm{H}, \mathrm{dd}, \mathrm{J}=2.1\right.$ and $\left.12.1 \mathrm{~Hz}, \mathrm{H}-5^{\prime} \mathrm{a}\right), 5.77\left(1 \mathrm{H}, \mathrm{dd}, \mathrm{J}=2.2\right.$ and $12.3 \mathrm{~Hz}, \mathrm{H}-5^{\prime} \mathrm{b}$ ), $5.67(1 \mathrm{H}, \mathrm{d}, \mathrm{J}=8.1 \mathrm{~Hz}, \mathrm{H}-5), 5.62\left(1 \mathrm{H}, \mathrm{s}, 3^{\prime}-\mathrm{OH}\right), 4.40(1 \mathrm{H}, \mathrm{dd}, \mathrm{J}=2.2$ and $\left.5.5 \mathrm{~Hz}, \mathrm{H}-4^{\prime}\right), 4.22\left(1 \mathrm{H}, \mathrm{d}, \mathrm{J}=5.6 \mathrm{~Hz}, \mathrm{H}-2^{\prime}\right), 4.17(1 \mathrm{H}, \mathrm{dd}, \mathrm{J}=7.4$ and $5.4 \mathrm{~Hz}$, $\left.\mathrm{H}-3^{\prime}\right), 2.34\left\{2 \mathrm{H}, \mathrm{m}, \mathrm{CH}_{3}\left(\mathrm{CH}_{2}\right)_{5} \mathrm{CH}_{2} \mathrm{CO}-\right\}, 1.61\left\{2 \mathrm{H}, \mathrm{m}, \mathrm{CH}_{3}\left(\mathrm{CH}_{2}\right)_{4} \mathrm{CH}_{2} \mathrm{CH}_{2} \mathrm{CO}-\right\}$, $1.26\left\{8 \mathrm{H}, \mathrm{m}, \mathrm{CH}_{3}\left(\mathrm{CH}_{2}\right)_{4}\left(\mathrm{CH}_{2}\right)_{2} \mathrm{CO}-\right\}, \mathrm{O} . .87\left\{3 \mathrm{H}, \mathrm{m}, \mathrm{CH}_{3}\left(\mathrm{CH}_{2}\right)_{6} \mathrm{CO}-\right\}$. Mass spectra (MS) (positive ion LC-ESI, 8eV): $m / z[\mathrm{M}+\mathrm{H}]^{+} 371.18$ (100). Anal calcd for $\mathrm{C}_{17} \mathrm{H}_{26} \mathrm{O}_{7} \mathrm{~N}_{2}$ (370.18): C, 55.15; H, 7.02. Found: C, 55.18; H, 7.04.

\section{General procedure for synthesis of $5^{\prime}$-O-octanoyl derivatives}

A cooled $\left(\mathrm{O}^{\circ} \mathrm{C}\right)$ and stirred solution of compound (2) $(120.8 \mathrm{mg}, 0.33 \mathrm{mmol})$ in dry pyridine $(3 \mathrm{ml})$ was treated with 5 molar equivalents of pentanoyl chloride (0.14 ml, $5.1 \mathrm{mmol}$ ) and the solution was left standing overnight in the room temperature. The progress of the reaction was monitored by t.l.c (methanolchloroform, 1:18) which indicated the complete conversion of the starting material into faster moving product $\left(R_{f}=0.54\right)$. Aqueous work-up procedure as described earlier and silica gel column chromatographic purification (methanol-chloroform, 1:18 as eluant), gave the pentanoylate (3) (110 mg, 91\%) as a 
pasty mass.

Using the similar reaction procedure, compound 3 was converted to compound 4, 5, 6, 7, 8, 9, 10, 11, 12 and compound 13 .

\section{$5^{\prime}$-O-Octanoyl-2', $\mathbf{3}^{\prime}$-di-O-pentanoyluridine (Compound 3)}

Colour: off white, solubility: $\mathrm{CHCl}_{3}$, DMF. FTIR (KBr) $v_{\max }\left(\mathrm{cm}^{-1}\right) 1757(\mathrm{C}=\mathrm{O})$.

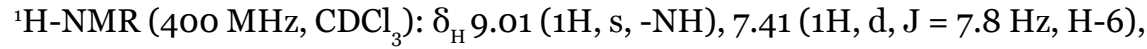
$6.08\left(1 \mathrm{H}, \mathrm{d}, \mathrm{J}=5.6 \mathrm{~Hz}, \mathrm{H}-1^{\prime}\right), 5.75\left(1 \mathrm{H}, \mathrm{dd}, \mathrm{J}=2.2\right.$ and $\left.12.2 \mathrm{~Hz}, \mathrm{H}-5^{\prime} \mathrm{a}\right), 5.61$ ( $1 \mathrm{H}, \mathrm{dd}, \mathrm{J}=2.1$ and $\left.12.2 \mathrm{~Hz}, \mathrm{H}^{-} 5^{\prime} \mathrm{b}\right), 5.08(1 \mathrm{H}, \mathrm{d}, \mathrm{J}=7.8 \mathrm{~Hz}, \mathrm{H}-5), 4.52(1 \mathrm{H}, \mathrm{d}$, $\mathrm{J}=5.2 \mathrm{~Hz}, \mathrm{H}-2^{\prime}$ ), 4.33 ( $1 \mathrm{H}, \mathrm{dd}, \mathrm{J}=7.7$ and $\left.5.6 \mathrm{~Hz} \mathrm{H}-3^{\prime}\right), 4.27\left(1 \mathrm{H}, \mathrm{m}, \mathrm{H}-4^{\prime}\right.$ ), $2.35\left\{4 \mathrm{H}, \mathrm{m}, 2 \times \mathrm{CH}_{3}\left(\mathrm{CH}_{2}\right)_{2} \mathrm{CH}_{2} \mathrm{CO}-\right\}, 2.31\left\{2 \mathrm{H}, \mathrm{m}, \mathrm{CH}_{3}\left(\mathrm{CH}_{2}\right)_{5} \mathrm{CH}_{2} \mathrm{CO}-\right\}, 1.61$ (4H, m, $\left.2 \times \mathrm{CH}_{3} \mathrm{CH}_{2} \mathrm{CH}_{2} \mathrm{CH}_{2} \mathrm{CO}-\right), 1.57\left\{2 \mathrm{H}, \mathrm{m}, \mathrm{CH}_{3}\left(\mathrm{CH}_{2}\right)_{4} \mathrm{CH}_{2} \mathrm{CH}_{2} \mathrm{CO}-\right\}, 1.38$ $\left\{4 \mathrm{H}, \mathrm{m}, 2 \times \mathrm{CH}_{3} \mathrm{CH}_{2}\left(\mathrm{CH}_{2}\right)_{2} \mathrm{CO}-\right\}, 1.26\left\{8 \mathrm{H}, \mathrm{m}, \mathrm{CH}_{3}\left(\mathrm{CH}_{2}\right)_{4}\left(\mathrm{CH}_{2}\right)_{2} \mathrm{CO}-\right\}, 0.88\{6 \mathrm{H}$, $\left.\mathrm{m}, 2 \times \mathrm{CH}_{3}\left(\mathrm{CH}_{2}\right)_{3} \mathrm{CO}-\right\}, 0.87\left\{3 \mathrm{H}, \mathrm{m}, \mathrm{CH}_{3}\left(\mathrm{CH}_{2}\right)_{6} \mathrm{CO}-\right\}$. Mass spectra (MS) (positive ion LC-ESI, 8eV): $\mathrm{m} / \mathrm{z}[\mathrm{M}+\mathrm{H}]^{+} 539.60$ (100). Anal calcd for $\mathrm{C}_{27} \mathrm{H}_{42} \mathrm{O}_{9} \mathrm{~N}_{2}$ (538.60): C, 60.17; H, 7.80. Found: C, 60.22; H, 7.84.

\section{$2^{\prime}, 3^{\prime}$-Di-O-hexanoyl-5' -O-octanoyluridine (Compound 4)}

Colour: white, solubility: $\mathrm{CHCl}_{3}$, DMF, DMSO. FTIR (KBr) $v_{\max }\left(\mathrm{cm}^{-1}\right) 1742$ $(\mathrm{C}=\mathrm{O}) .{ }^{1} \mathrm{H}-\mathrm{NMR}\left(400 \mathrm{MHz}, \mathrm{CDCl}_{3}\right): \delta_{\mathrm{H}} 9.98(1 \mathrm{H}, \mathrm{s},-\mathrm{NH}), 7.53(1 \mathrm{H}, \mathrm{d}, \mathrm{J}=7.6 \mathrm{~Hz}$, H-6), 6.02 ( $1 \mathrm{H}, \mathrm{d}, \mathrm{J}=5.7 \mathrm{~Hz}, \mathrm{H}-1^{\prime}$ ), 5.89 ( $1 \mathrm{H}, \mathrm{dd}, \mathrm{J}=2.2$ and $12.2 \mathrm{~Hz}, \mathrm{H}-5^{\prime} \mathrm{a}$ ), $5.74\left(1 \mathrm{H}, \mathrm{dd}, \mathrm{J}=2.1\right.$ and $\left.12.0 \mathrm{~Hz}, \mathrm{H}-5^{\prime} \mathrm{b}\right), 5.45$ ( $1 \mathrm{H}, \mathrm{d}, \mathrm{J}=7.8 \mathrm{~Hz}, \mathrm{H}-5$ ), 4.95 $\left(1 \mathrm{H}, \mathrm{d}, \mathrm{J}=5.2 \mathrm{~Hz}, \mathrm{H}-2^{\prime}\right.$ ), $4.39\left(1 \mathrm{H}, \mathrm{dd}, \mathrm{J}=7.8\right.$ and $\left.5.6 \mathrm{~Hz} \mathrm{H}-3^{\prime}\right), 4.18(1 \mathrm{H}, \mathrm{m}$, $\left.\mathrm{H}-4^{\prime}\right), 2.40\left\{2 \mathrm{H}, \mathrm{m}, \mathrm{CH}_{3}\left(\mathrm{CH}_{2}\right)_{5} \mathrm{CH}_{2} \mathrm{CO}-\right\}, 2.35\left\{4 \mathrm{H}, \mathrm{m}, 2 \times \mathrm{CH}_{3}\left(\mathrm{CH}_{2}\right)_{3} \mathrm{CH}_{2} \mathrm{CO}-\right\}$, $1.62\left\{4 \mathrm{H}, \mathrm{m}, 2 \times \mathrm{CH}_{3}\left(\mathrm{CH}_{2}\right)_{2} \mathrm{CH}_{2} \mathrm{CH}_{2} \mathrm{CO}-\right\}, 1.60\left\{2 \mathrm{H}, \mathrm{m}, \mathrm{CH}_{3}\left(\mathrm{CH}_{2}\right)_{4} \mathrm{CH}_{2} \mathrm{CH}_{2} \mathrm{CO}-\right\}$, $1.27\left\{8 \mathrm{H}, \mathrm{m}, 2 \times \mathrm{CH}_{3}\left(\mathrm{CH}_{2}\right)_{2} \mathrm{CH}_{2} \mathrm{CH}_{2} \mathrm{CO}-\right\}, 1.25\left\{8 \mathrm{H}, \mathrm{m}, \mathrm{CH}_{3}\left(\mathrm{CH}_{2}\right)_{4}\left(\mathrm{CH}_{2}\right)_{2} \mathrm{CO}-\right\}$, $0.85\left\{6 \mathrm{H}, \mathrm{m}, 2 \times \mathrm{CH}_{3}\left(\mathrm{CH}_{2}\right)_{4} \mathrm{CO}-\right\}, 0 . .84\left\{3 \mathrm{H}, \mathrm{m}, \mathrm{CH}_{3}\left(\mathrm{CH}_{2}\right)_{6} \mathrm{CO}-\right\}$.

Mass spectra (MS) (positive ion LC-ESI, 8eV): $m / z[\mathrm{M}+\mathrm{H}]^{+} 567.5$ (100). Anal calcd for $\mathrm{C}_{29} \mathrm{H}_{46} \mathrm{O}_{9} \mathrm{~N}_{2}$ (566.50): C, 61.43; H, 8.12. Found: C, 61.46; H, 8.15.

\section{$\mathbf{2}^{\prime}, 3^{\prime}$-Di-O-decanoyl-5' ${ }^{\prime}-O$-octanoyluridine (Compound 5 )}

Colour: dark white, solubility: $\mathrm{CHCl}_{3}, \mathrm{DMF}$, DMSO. FTIR $(\mathrm{KBr}) \mathrm{v}_{\max }\left(\mathrm{cm}^{-1}\right)$ $1738(\mathrm{C}=\mathrm{O}) .{ }^{1} \mathrm{H}-\mathrm{NMR}\left(400 \mathrm{MHz}, \mathrm{CDCl}_{3}\right): \delta_{\mathrm{H}} 9.05(1 \mathrm{H}, \mathrm{s},-\mathrm{NH}), 7.54(1 \mathrm{H}, \mathrm{d}, \mathrm{J}$ $=7.8 \mathrm{~Hz}, \mathrm{H}-6), 5.87\left(1 \mathrm{H}, \mathrm{d}, \mathrm{J}=5.6 \mathrm{~Hz}, \mathrm{H}-1^{\prime}\right), 5.79(1 \mathrm{H}, \mathrm{dd}, \mathrm{J}=2.0$ and 12.0 Hz, H-5 $\left.{ }^{\prime} \mathrm{a}\right), 5.41$ ( $1 \mathrm{H}, \mathrm{dd}, \mathrm{J}=2.0$ and $\left.12.0 \mathrm{~Hz}, \mathrm{H}-5^{\prime} \mathrm{b}\right), 5.41(1 \mathrm{H}, \mathrm{d}, \mathrm{J}=8.2 \mathrm{~Hz}$, H-5), 5.02 ( $\left.1 \mathrm{H}, \mathrm{m}, \mathrm{H}-2^{\prime}\right), 4.38\left(1 \mathrm{H}, \mathrm{m}, \mathrm{H}-3^{\prime}\right), 4.28\left(1 \mathrm{H}, \mathrm{m}, \mathrm{H}-4^{\prime}\right), 2.36\{4 \mathrm{H}$, $\left.\mathrm{m}, 2 \times \mathrm{CH}_{3}\left(\mathrm{CH}_{2}\right)_{7} \mathrm{CH}_{2} \mathrm{CO}-\right\}, 2.33\left\{2 \mathrm{H}, \mathrm{m}, \mathrm{CH}_{3}\left(\mathrm{CH}_{2}\right)_{5} \mathrm{CH}_{2} \mathrm{CO}-\right\}, 1.60\{4 \mathrm{H}, \mathrm{m}$, $\left.2 \times \mathrm{CH}_{3}\left(\mathrm{CH}_{2}\right)_{6} \mathrm{CH}_{2} \mathrm{CH}_{2} \mathrm{CO}-\right\}, 1.57\left\{2 \mathrm{H}, \mathrm{m}, \mathrm{CH}_{3}\left(\mathrm{CH}_{2}\right)_{4} \mathrm{CH}_{2} \mathrm{CH}_{2} \mathrm{CO}-\right\}, 1.26\{24 \mathrm{H}$, m, $\left.2 \times \mathrm{CH}_{3}\left(\mathrm{CH}_{2}\right)_{6} \mathrm{CH}_{2} \mathrm{CH}_{2} \mathrm{CO}-\right\}, 1.24\left\{8 \mathrm{H}, \mathrm{m}, \mathrm{CH}_{3}\left(\mathrm{CH}_{2}\right)_{4}\left(\mathrm{CH}_{2}\right)_{2} \mathrm{CO}-\right\}, 0.85\{6 \mathrm{H}$, 
m, $\left.2 \times \mathrm{CH}_{3}\left(\mathrm{CH}_{2}\right)_{8} \mathrm{CO}-\right\}, 0.83\left\{3 \mathrm{H}, \mathrm{m}, \mathrm{CH}_{3}\left(\mathrm{CH}_{2}\right)_{6} \mathrm{CO}-\right\}$. Mass spectra (MS) (positive ion LC-ESI, 8eV): $m / z[M+H]^{+} 680.29$ (100). Anal calcd for $\mathrm{C}_{37} \mathrm{H}_{62} \mathrm{O}_{9} \mathrm{~N}_{2}$ (679.29): C, 65.36; H, 9.13. Found: C, 65.40; H, 9.14.

\section{2', $^{\prime}$ '-Di-O-lauroyl-5' -O-octanoyluridine (Compound 6)}

Colour: deep white, solubility: $\mathrm{CHCl}_{3}, \mathrm{DMF}$, DMSO. FTIR $(\mathrm{KBr}) v_{\max }\left(\mathrm{cm}^{-1}\right)$ 1758 (-CO). ${ }^{1} \mathrm{H}-\mathrm{NMR}\left(400 \mathrm{MHz}, \mathrm{CDCl}_{3}\right): \delta_{\mathrm{H}} 8.96(1 \mathrm{H}, \mathrm{s},-\mathrm{NH}), 7.42(1 \mathrm{H}, \mathrm{d}, \mathrm{J}$ = $7.7 \mathrm{~Hz}, \mathrm{H}-6), 6.00\left(1 \mathrm{H}, \mathrm{m}, \mathrm{H}-1^{\prime}\right), 5.76\left(1 \mathrm{H}, \mathrm{m}, \mathrm{H}-5^{\prime} \mathrm{a}\right), 5.57\left(1 \mathrm{H}, \mathrm{m}, \mathrm{H}-5^{\prime} \mathrm{b}\right)$, $5.48(1 \mathrm{H}, \mathrm{d}, \mathrm{J}=8.1 \mathrm{~Hz}, \mathrm{H}-5), 5.29\left(1 \mathrm{H}, \mathrm{d}, \mathrm{J}=5.6 \mathrm{~Hz}, \mathrm{H}-2^{\prime}\right), 5.22(1 \mathrm{H}, \mathrm{m}$, $\left.\mathrm{H}-3^{\prime}\right), 4.32\left(1 \mathrm{H}, \mathrm{m}, \mathrm{H}-4^{\prime}\right), 2.37\left\{4 \mathrm{H}, \mathrm{m}, 2 \times \mathrm{CH}_{3}\left(\mathrm{CH}_{2}\right)_{9} \mathrm{CH}_{2} \mathrm{CO}-\right\}, 2.31\{2 \mathrm{H}, \mathrm{m}$, $\left.\mathrm{CH}_{3}\left(\mathrm{CH}_{2}\right)_{5} \mathrm{CH}_{2} \mathrm{CO}-\right\}, 1.59\left\{4 \mathrm{H}, \mathrm{m}, 2 \times \mathrm{CH}_{3}\left(\mathrm{CH}_{2}\right)_{8} \mathrm{CH}_{2} \mathrm{CH}_{2} \mathrm{CO}-\right\}, 1.56\{2 \mathrm{H}, \mathrm{m}$, $\left.\mathrm{CH}_{3}\left(\mathrm{CH}_{2}\right)_{4} \mathrm{CH}_{2} \mathrm{CH}_{2} \mathrm{CO}-\right\}, 1.24\left\{8 \mathrm{H}, \mathrm{m}, \mathrm{CH}_{3}\left(\mathrm{CH}_{2}\right)_{4}\left(\mathrm{CH}_{2}\right)_{2} \mathrm{CO}-\right\}, 1.21\{32 \mathrm{H}, \mathrm{m}$, $\left.2 \times \mathrm{CH}_{3}\left(\mathrm{CH}_{2}\right)_{8} \mathrm{CH}_{2} \mathrm{CH}_{2} \mathrm{CO}-\right\}, 0.88\left\{6 \mathrm{H}, \mathrm{m}, 2 \times \mathrm{CH}_{3}\left(\mathrm{CH}_{2}\right)_{10} \mathrm{CO}-\right\}, 0 . .86\{3 \mathrm{H}, \mathrm{m}$, $\left.\mathrm{CH}_{3}\left(\mathrm{CH}_{2}\right)_{6} \mathrm{CO}-\right\}$. Mass spectra (MS) (positive ion LC-ESI, $8 \mathrm{eV}$ ): $\mathrm{m} / z[\mathrm{M}+\mathrm{H}]^{+}$ 735.42 (100). Anal calcd for $\mathrm{C}_{41} \mathrm{H}_{70} \mathrm{O}_{9} \mathrm{~N}_{2}$ (734.42): C, 67.04; H, 9.53. Found: C, 67.07; H, 9.56.

\section{$2^{\prime}, 3^{\prime}$-Di-O-myristoyl-5' -O-octanoyluridine (Compound 7)}

Colour: deep white, solubility: $\mathrm{CHCl}_{3}$, DMF, DMSO. FTIR $(\mathrm{KBr}) v_{\max }\left(\mathrm{cm}^{-1}\right) 1736$ (-CO). ${ }^{1} \mathrm{H}-\mathrm{NMR}\left(400 \mathrm{MHz}, \mathrm{CDCl}_{3}\right.$ ): $\delta_{\mathrm{H}} 9.01(1 \mathrm{H}, \mathrm{s},-\mathrm{NH}), 7.50(1 \mathrm{H}, \mathrm{d}, \mathrm{J}=7.6 \mathrm{~Hz}$, H-6), 6.08 ( $1 \mathrm{H}, \mathrm{d}, \mathrm{J}=5.7 \mathrm{~Hz}, \mathrm{H}-1^{\prime}$ ), 5.75 (1H, m, H-5'a), 5.73 (1H, m, H-5'b), $5.61(1 \mathrm{H}, \mathrm{d}, \mathrm{J}=7.7 \mathrm{~Hz}, \mathrm{H}-5), 5.08\left(1 \mathrm{H}, \mathrm{d}, \mathrm{J}=5.3 \mathrm{~Hz}, \mathrm{H}-2^{\prime}\right), 4.78$ (1H, m, H-3'), $4.37\left(1 \mathrm{H}, \mathrm{dd}, \mathrm{J}=2.1\right.$ and $\left.5.5 \mathrm{~Hz}, \mathrm{H}-4^{\prime}\right), 2.35\left\{4 \mathrm{H}, \mathrm{m}, 2 \times \mathrm{CH}_{3}\left(\mathrm{CH}_{2}\right)_{11} \mathrm{CH}_{2} \mathrm{CO}-\right\}$, $2.33\left\{2 \mathrm{H}, \mathrm{m}, \mathrm{CH}_{3}\left(\mathrm{CH}_{2}\right)_{5} \mathrm{CH}_{2} \mathrm{CO}-\right\}, 1.62\left\{2 \mathrm{H}, \mathrm{m}, \mathrm{CH}_{3}\left(\mathrm{CH}_{2}\right)_{4} \mathrm{CH}_{2} \mathrm{CH}_{2} \mathrm{CO}-\right\}, 1.26$ $\left\{44 \mathrm{H}, \mathrm{m}, 2 \times \mathrm{CH}_{3}\left(\mathrm{CH}_{2}\right)_{11} \mathrm{CH}_{2} \mathrm{CO}-\right\}, 1.25\left\{8 \mathrm{H}, \mathrm{m}, \mathrm{CH}_{3}\left(\mathrm{CH}_{2}\right)_{4}\left(\mathrm{CH}_{2}\right)_{2} \mathrm{CO}-\right\}, 0.88$ $\left\{6 \mathrm{H}, \mathrm{m}, 2 \times \mathrm{CH}_{3}\left(\mathrm{CH}_{2}\right)_{12} \mathrm{CO}-\right\}, \mathrm{O} .86\left\{3 \mathrm{H}, \mathrm{m}, \mathrm{CH}_{3}\left(\mathrm{CH}_{2}\right)_{6} \mathrm{CO}-\right\}$. Mass spectra (MS) (positive ion LC-ESI, 8eV): $m / z[\mathrm{M}+\mathrm{H}]^{+} 791.46$ (100). Anal calcd for $\mathrm{C}_{45} \mathrm{H}_{78} \mathrm{O}_{9} \mathrm{~N}_{2}$ (790.46): C, 68.37; H, 9.87. Found: C, 68.41; H, 9.89.

\section{$5^{\prime}$-O-Octanoyl-2', $3^{\prime}$-di-O-palmitoyluridine (Compound 8)}

Colour: light white, solubility: $\mathrm{CHCl}_{3}, \mathrm{DMF}$, DMSO. FTIR $(\mathrm{KBr}) v_{\max }\left(\mathrm{cm}^{-1}\right)$ $1722(-\mathrm{CO}) \mathrm{cm}^{-1} \cdot{ }^{1} \mathrm{H}-\mathrm{NMR}\left(400 \mathrm{MHz} \mathrm{CDCl}_{3}\right): \delta_{\mathrm{H}} 8.98(1 \mathrm{H}, \mathrm{s},-\mathrm{NH}), 7.58(1 \mathrm{H}$, m, H-6), $5.70\left(1 \mathrm{H}, \mathrm{m}, \mathrm{H}-1^{\prime}\right), 5.61\left(2 \mathrm{H}, \mathrm{m}, \mathrm{H}-5^{\prime} \mathrm{a}\right.$ and $\left.\mathrm{H}-5^{\prime} \mathrm{b}\right), 5.46(1 \mathrm{H}, \mathrm{d}, \mathrm{J}=$ $8.1 \mathrm{~Hz}, \mathrm{H}-5), 5.02\left(1 \mathrm{H}, \mathrm{d}, \mathrm{J}=5.5 \mathrm{~Hz}, \mathrm{H}-2^{\prime}\right), 4.87\left(1 \mathrm{H}, \mathrm{m}, \mathrm{H}-3^{\prime}\right), 4.36(1 \mathrm{H}, \mathrm{m}$, $\left.\mathrm{H}-4^{\prime}\right), 2.36\left\{4 \mathrm{H}, \mathrm{m}, 2 \times \mathrm{CH}_{3}\left(\mathrm{CH}_{2}\right)_{13} \mathrm{CH}_{2} \mathrm{CO}-\right\}, 2.33\left\{2 \mathrm{H}, \mathrm{m}, \mathrm{CH}_{3}\left(\mathrm{CH}_{2}\right)_{5} \mathrm{CH}_{2} \mathrm{CO}-\right\}$, $1.6 \mathrm{O}\left\{2 \mathrm{H}, \mathrm{m}, \mathrm{CH}_{3}\left(\mathrm{CH}_{2}\right)_{4} \mathrm{CH}_{2} \mathrm{CH}_{2} \mathrm{CO}-\right\}, 1.25\left\{8 \mathrm{H}, \mathrm{m}, \mathrm{CH}_{3}\left(\mathrm{CH}_{2}\right)_{4}\left(\mathrm{CH}_{2}\right)_{2} \mathrm{CO}-\right\}$, $1.24\left\{52 \mathrm{H}, \mathrm{m}, 2 \times \mathrm{CH}_{3}\left(\mathrm{CH}_{2}\right)_{13} \mathrm{CH}_{2} \mathrm{CO}-\right\}, 0.88\left\{6 \mathrm{H}, \mathrm{m}, 2 \times \mathrm{CH}_{3}\left(\mathrm{CH}_{2}\right)_{14} \mathrm{CO}-\right\}, 0.86$ $\left\{3 \mathrm{H}, \mathrm{m}, \mathrm{CH}_{3}\left(\mathrm{CH}_{2}\right)_{6} \mathrm{CO}-\right\}$. Mass spectra (MS) (positive ion LC-ESI, $8 \mathrm{eV}$ ): $\mathrm{m} / \mathrm{z}$ $[\mathrm{M}+\mathrm{H}]^{+} 847.5$ (100). Anal calcd for $\mathrm{C}_{49} \mathrm{H}_{86} \mathrm{O}_{9} \mathrm{~N}_{2}$ (846.50): C, 69.52; H, 10.16 . Found: C, 69.55; H, 10.19 . 


\section{$5^{\prime}$-O-Octanoyl-2', $3^{\prime}$-di-O-pivaloyluridine (Compound 9)}

Colour: white, solubility: $\mathrm{CHCl}_{3}$, DMF, DMSO. FTIR $(\mathrm{KBr}) v_{\max }\left(\mathrm{cm}^{-1}\right) 1740(-\mathrm{CO})$. ${ }^{1} \mathrm{H}-\mathrm{NMR}\left(400 \mathrm{MHz}, \mathrm{CDCl}_{3}\right.$ ): $\delta_{\mathrm{H}} 9.06(1 \mathrm{H}, \mathrm{s},-\mathrm{NH}), 7.65(1 \mathrm{H}, \mathrm{d}, \mathrm{J}=7.6 \mathrm{~Hz}, \mathrm{H}-6)$, 6.08 ( $1 \mathrm{H}, \mathrm{d}, \mathrm{J}=5.6 \mathrm{~Hz}, \mathrm{H}-1^{\prime}$ ), 5.78 ( $1 \mathrm{H}, \mathrm{m}, \mathrm{H}-5^{\prime}$ a), 5.61 ( $\left.1 \mathrm{H}, \mathrm{m}, \mathrm{H}-5^{\prime} \mathrm{b}\right), 5.29$ $(1 \mathrm{H}, \mathrm{d}, \mathrm{J}=8.4 \mathrm{~Hz}, \mathrm{H}-5), 5.01\left(1 \mathrm{H}, \mathrm{m}, \mathrm{H}-2^{\prime}\right), 4.60\left(1 \mathrm{H}, \mathrm{m}, \mathrm{H}-3^{\prime}\right), 4.38(1 \mathrm{H}, \mathrm{m}$, $\left.\mathrm{H}-4^{\prime}\right), 2.35\left\{2 \mathrm{H}, \mathrm{m}, \mathrm{CH}_{3}\left(\mathrm{CH}_{2}\right)_{5} \mathrm{CH}_{2} \mathrm{CO}-\right\}, 1.64\left\{2 \mathrm{H}, \mathrm{m}, \mathrm{CH}_{3}\left(\mathrm{CH}_{2}\right)_{4} \mathrm{CH}_{2} \mathrm{CH}_{2} \mathrm{CO}-\right\}$, $1.21\left\{18 \mathrm{H}, \mathrm{s}, 2 \times\left(\mathrm{CH}_{3}\right)_{3} \mathrm{CCO}-\right\}, 1.21\left\{8 \mathrm{H}, \mathrm{m}, \mathrm{CH}_{3}\left(\mathrm{CH}_{2}\right)_{4}\left(\mathrm{CH}_{2}\right)_{2} \mathrm{CO}-\right\}, 0 . .88\{3 \mathrm{H}$, m, $\left.\mathrm{CH}_{3}\left(\mathrm{CH}_{2}\right)_{6} \mathrm{CO}-\right\}$. Mass spectra (MS) (positive ion LC-ESI, $8 \mathrm{eV}$ ): $\mathrm{m} / \mathrm{z}[\mathrm{M}+\mathrm{H}]^{+}$ 539.5 (100). Anal calcd for $\mathrm{C}_{27} \mathrm{H}_{42} \mathrm{O}_{9} \mathrm{~N}_{2}$ (538.50): C, 60.17; H, 7.80. Found: C, 60.19; H, 7.84 .

\section{2', $^{\prime} \mathbf{3}^{\prime}$-Di-O-methanesulfonyl-5' $-O$-octanoyluridine (Compound 10)}

Colour: white, solubility: $\mathrm{CHCl}_{3}$, DMF, DMSO. FTIR (KBr) $v_{\max }\left(\mathrm{cm}^{-1}\right) 1765$ (-CO) and $1365\left(-\mathrm{SO}_{2}\right)$. ${ }^{1} \mathrm{H}-\mathrm{NMR}\left(400 \mathrm{MHz}, \mathrm{CDCl}_{3}\right)$ : $\delta_{\mathrm{H}} 8.91(1 \mathrm{H}, \mathrm{s},-\mathrm{NH}), 7.71$ $(1 \mathrm{H}, \mathrm{d}, \mathrm{J}=7.8 \mathrm{~Hz}, \mathrm{H}-6), 6.01\left(1 \mathrm{H}, \mathrm{d}, \mathrm{J}=5.6 \mathrm{~Hz}, \mathrm{H}-1^{\prime}\right), 5.88\left(1 \mathrm{H}, \mathrm{m}, \mathrm{H}-5^{\prime} \mathrm{a}\right)$, $5.69\left(1 \mathrm{H}, \mathrm{m}, \mathrm{H}-5^{\prime} \mathrm{b}\right), 5.22(1 \mathrm{H}, \mathrm{d}, \mathrm{J}=8.2 \mathrm{~Hz}, \mathrm{H}-5), 5.15$ (1H, m, H-2') 4.96 $\left(1 \mathrm{H}, \mathrm{m}, \mathrm{H}-3^{\prime}\right), 4.41\left(1 \mathrm{H}, \mathrm{m}, \mathrm{H}-4^{\prime}\right), 3.10,3.05\left\{2 \times 3 \mathrm{H}, 2 \times \mathrm{s}, 2 \times \mathrm{CH}_{3} \mathrm{SO}_{2}-\right\}, 2.36$ $\left\{2 \mathrm{H}, \mathrm{m}, \mathrm{CH}_{3}\left(\mathrm{CH}_{2}\right)_{5} \mathrm{CH}_{2} \mathrm{CO}-\right\}, 1.61\left\{2 \mathrm{H}, \mathrm{m}, \mathrm{CH}_{3}\left(\mathrm{CH}_{2}\right)_{4} \mathrm{CH}_{2} \mathrm{CH}_{2} \mathrm{CO}-\right\}, 1.26\{8 \mathrm{H}, \mathrm{m}$, $\left.\mathrm{CH}_{3}\left(\mathrm{CH}_{2}\right)_{4}\left(\mathrm{CH}_{2}\right)_{2} \mathrm{CO}-\right\}, 0 . .86\left\{3 \mathrm{H}, \mathrm{m}, \mathrm{CH}_{3}\left(\mathrm{CH}_{2}\right)_{6} \mathrm{CO}-\right\}$. Mass spectra (MS) (positive ion LC-ESI, 8eV): $\mathrm{m} / z$ [M+H] $]^{+} 527.32$ (100). Anal calcd for $\mathrm{C}_{19} \mathrm{H}_{30} \mathrm{O}_{11} \mathrm{~N}_{2} \mathrm{~S}_{2}$ (526.32): C, 43.36; H, 5.70. Found: C, 43.39; H, 5.73.

\section{$\mathbf{2}^{\prime}, \mathbf{3}^{\prime}$-Di-O-benzenesulfonyl-5' $-\mathrm{O}$-octanoyluridine (Compound 11)}

Colour: light white, solubility: $\mathrm{CHCl}_{3}, \mathrm{DMF}, \mathrm{DMSO}$. FTIR $(\mathrm{KBr}) \mathrm{v}_{\max }\left(\mathrm{cm}^{-}\right.$ 1) $1741(-\mathrm{CO})$ and $1362\left(-\mathrm{SO}_{2}\right) .{ }^{1} \mathrm{H}-\mathrm{NMR}\left(400 \mathrm{MHz}, \mathrm{CDCl}_{3}\right): \delta_{\mathrm{H}} 9.09(1 \mathrm{H}, \mathrm{s}$, -NH), 7.90 (4H, m, Ar-H), 7.56 (2H, m, Ar-H), $7.41(4 \mathrm{H}, \mathrm{m}, \mathrm{Ar}-\mathrm{H}), 6.03(1 \mathrm{H}$, d, J = 7.7 Hz, H-6), $5.76\left(1 \mathrm{H}, \mathrm{d}, \mathrm{J}=5.5 \mathrm{~Hz}, \mathrm{H}-1^{\prime}\right.$ ), $5.30\left(1 \mathrm{H}, \mathrm{m}, \mathrm{H}-5^{\prime} \mathrm{a}\right), 5.09$ ( $\left.1 \mathrm{H}, \mathrm{m}, \mathrm{H}-5^{\prime} \mathrm{b}\right), 4.94(1 \mathrm{H}, \mathrm{d}, \mathrm{J}=8.2 \mathrm{~Hz}, \mathrm{H}-5), 4.76\left(1 \mathrm{H}, \mathrm{m}, \mathrm{H}-2^{\prime}\right), 4.56(1 \mathrm{H}$, $\left.\mathrm{m}, \mathrm{H}-3^{\prime}\right), 4.35\left(1 \mathrm{H}, \mathrm{m}, \mathrm{H}-4^{\prime}\right), 2.33\left\{2 \mathrm{H}, \mathrm{m}, \mathrm{CH}_{3}\left(\mathrm{CH}_{2}\right)_{5} \mathrm{CH}_{2} \mathrm{CO}-\right\}, 1.62\{2 \mathrm{H}, \mathrm{m}$, $\left.\mathrm{CH}_{3}\left(\mathrm{CH}_{2}\right)_{4} \mathrm{CH}_{2} \mathrm{CH}_{2} \mathrm{CO}-\right\}, 1.26\left\{8 \mathrm{H}, \mathrm{m}, \mathrm{CH}_{3}\left(\mathrm{CH}_{2}\right)_{4}\left(\mathrm{CH}_{2}\right)_{2} \mathrm{CO}-\right\}, 0 . .87\{3 \mathrm{H}, \mathrm{m}$, $\left.\mathrm{CH}_{3}\left(\mathrm{CH}_{2}\right)_{6} \mathrm{CO}-\right\}$. Mass spectra (MS) (positive ion LC-ESI, 8eV): $\mathrm{m} / \mathrm{z}[\mathrm{M}+\mathrm{H}]^{+}$ 651.42 (100). Anal calcd for $\mathrm{C}_{29} \mathrm{H}_{34} \mathrm{O}_{11} \mathrm{~N}_{2} \mathrm{~S}_{2}$ (650.42): C, 53.55; H, 5.23. Found: C, 53.56; H, 5.27 .

\section{$2^{\prime}, 3^{\prime}$-Di-O-(2-bromobenzoyl)-5' $-O$-octanoyluridine (Compound 12)}

Colour: white, solubility: $\mathrm{CHCl}_{3}$, DMF, DMSO. FTIR ( $\left.\mathrm{KBr}\right) \mathrm{v}_{\max }\left(\mathrm{cm}^{-1}\right) 1780$ (-CO). ${ }^{1} \mathrm{H}-\mathrm{NMR}\left(400 \mathrm{MHz}, \mathrm{CDCl}_{3}\right.$ ): $\delta_{\mathrm{H}} 9.01(1 \mathrm{H}, \mathrm{s},-\mathrm{NH}), 7.81(2 \mathrm{H}, \mathrm{m}, \mathrm{Ar}-\mathrm{H})$, $7.64(4 \mathrm{H}, \mathrm{m}, \mathrm{Ar}-\mathrm{H}), 7.36(2 \mathrm{H}, \mathrm{m}, \mathrm{Ar}-\mathrm{H}), 7.28(1 \mathrm{H}, \mathrm{d}, \mathrm{J}=7.6 \mathrm{~Hz}, \mathrm{H}-6), 6.19$ $\left(1 \mathrm{H}, \mathrm{d}, \mathrm{J}=5.6 \mathrm{~Hz}, \mathrm{H}-1^{\prime}\right), 6.03\left(1 \mathrm{H}, \mathrm{m}, \mathrm{H}-5^{\prime} \mathrm{a}\right), 5.77(1 \mathrm{H}, \mathrm{dd}, \mathrm{J}=2.0$ and 12.0 
Hz, H-5'b), 5.55 (1H, d, J = 8.2 Hz, H-5), 5.49 (1H, m, H-2' ), $4.62(1 \mathrm{H}, \mathrm{m}$, $\left.\mathrm{H}-3^{\prime}\right), 4.36\left(1 \mathrm{H}, \mathrm{m}, \mathrm{H}-4^{\prime}\right), 2.34\left\{2 \mathrm{H}, \mathrm{m}, \mathrm{CH}_{3}\left(\mathrm{CH}_{2}\right)_{5} \mathrm{CH}_{2} \mathrm{CO}-\right\}, 1.62\{2 \mathrm{H}, \mathrm{m}$, $\left.\mathrm{CH}_{3}\left(\mathrm{CH}_{2}\right)_{4} \mathrm{CH}_{2} \mathrm{CH}_{2} \mathrm{CO}-\right\}, 1.24\left\{8 \mathrm{H}, \mathrm{m}, \mathrm{CH}_{3}\left(\mathrm{CH}_{2}\right)_{4}\left(\mathrm{CH}_{2}\right)_{2} \mathrm{CO}-\right\}, 0 . .84\{3 \mathrm{H}, \mathrm{m}$, $\left.\mathrm{CH}_{3}\left(\mathrm{CH}_{2}\right)_{6} \mathrm{CO}-\right\}$. Mass spectra (MS) (positive ion LC-ESI, 8eV): $\mathrm{m} / z[\mathrm{M}+\mathrm{H}]^{+}$ 737.41 (100). Anal calcd for $\mathrm{C}_{31} \mathrm{H}_{32} \mathrm{O}_{9} \mathrm{~N}_{2} \mathrm{Br}_{2}$ (736.41): C, 50.56; H, 4.35. Found: C, 50.59; H, 4.39 .

\section{$2^{\prime}, 3^{\prime}$-Di-O-(4-chlorobenzoyl)-5' -O-octanoyluridine (Compound 13)}

Colour: off white, solubility: $\mathrm{CHCl}_{3}, \mathrm{DMF}$, DMSO. FTIR $(\mathrm{KBr}) v_{\max }\left(\mathrm{cm}^{-1}\right) 1760$ $(\mathrm{C}=\mathrm{O}) .{ }^{1} \mathrm{H}-\mathrm{NMR}\left(400 \mathrm{MHz}, \mathrm{CDCl}_{3}\right) \delta_{\mathrm{H}}$ : $9.0(1 \mathrm{H}, \mathrm{s},-\mathrm{NH}), 7.95(4 \mathrm{H}, \mathrm{m}, \mathrm{Ar}-\mathrm{H})$, $7.75(1 \mathrm{H}, \mathrm{d}, \mathrm{J}=7.7 \mathrm{~Hz}, \mathrm{H}-6), 7.50(4 \mathrm{H}, \mathrm{m}, \mathrm{Ar}-\mathrm{H}), 6.03(1 \mathrm{H}, \mathrm{d}, \mathrm{J}=5.5 \mathrm{~Hz}$, $\left.\mathrm{H}-1^{\prime}\right), 5.79\left(1 \mathrm{H}, \mathrm{m}, \mathrm{H}-5^{\prime} \mathrm{a}\right), 5.77\left(1 \mathrm{H}, \mathrm{dd}, \mathrm{J}=2.1\right.$ and $\left.12.2 \mathrm{~Hz}, \mathrm{H}-5^{\prime} \mathrm{b}\right), 5.59$ (1H, m, H-5), 5.23 (1H, m, H-2' ), 4.55 (1H, m, H-3' ), 4.35 (1H, m, H-4' ), 2.33 $\left\{2 \mathrm{H}, \mathrm{m}, \mathrm{CH}_{3}\left(\mathrm{CH}_{2}\right)_{5} \mathrm{CH}_{2} \mathrm{CO}-\right\}, 1.62\left\{2 \mathrm{H}, \mathrm{m}, \mathrm{CH}_{3}\left(\mathrm{CH}_{2}\right)_{4} \mathrm{CH}_{2} \mathrm{CH}_{2} \mathrm{CO}-\right\}, 1.27\{8 \mathrm{H}$, $\left.\mathrm{m}, \mathrm{CH}_{3}\left(\mathrm{CH}_{2}\right)_{4}\left(\mathrm{CH}_{2}\right)_{2} \mathrm{CO}-\right\}, 0.84\left\{3 \mathrm{H}, \mathrm{m}, \mathrm{CH}_{3}\left(\mathrm{CH}_{2}\right)_{6} \mathrm{CO}-\right\}$. Mass spectra (MS) (positive ion LC-ESI, 8eV): $m / z[\mathrm{M}+\mathrm{H}]^{+} 648.6$ (100). Anal calcd for $\mathrm{C}_{31} \mathrm{H}_{32} \mathrm{O}_{9} \mathrm{~N}-$ ${ }_{2} \mathrm{Cl}_{2}$ (647.60): C, 57.52; H, 4.94. Found: C, 57.55; H, 4.98.

\section{Microbial screening studies}

Test tube cultures of bacterial pathogens were obtained from the Microbiology Laboratory, Department of Microbiology, University of Chittagong. The synthesized test compounds (Table $2 \& 3$ ) were subjected to antibacterial screening against three Gram-positive and three Gram-negative bacterial strains (Table 1).

\section{Preparation of bacterial suspension}

About $10 \mathrm{ml}$ of distilled water was taken in a clean screw cap test tube. A number of test tubes with water were sterilized in an autoclave. From 48 hours; old bacterial culture, one loop of bacterial culture was transferred to the sterilized distilled water and mixed it properly. These bacterial suspensions of the test tube were used to the pour plate during sensitivity test. 
Table 1. List of used bacteria and fungus.

\begin{tabular}{|c|c|c|}
\hline Types of organisms & Tested organisms \& strai & no. \\
\hline & Bacteria & \\
\hline \multirow{2}{*}{ Gram +Ve } & Bacillus subtilis & BTCC 17 \\
\hline & Bacillus cereus & BTCC 19 \\
\hline \multirow{6}{*}{ Gram -Ve } & Escherichia coli & ATCC 25922 \\
\hline & Pseudomonas aeruginosa & ICDDR,B \\
\hline & Salmonella typhi & AE 14612 \\
\hline & \multicolumn{2}{|l|}{ Fungus } \\
\hline & Aspergillus niger & ATCC 16404 \\
\hline & Rhizopous nigricans & ATCC 6227b \\
\hline
\end{tabular}

\section{Antibacterial efficacy test}

The in vitro antibacterial activities of the synthesized chemicals were detected by disc diffusion method ${ }^{30,31}$. Paper discs of $4 \mathrm{~mm}$ in diameter and glass petri plate of $90 \mathrm{~mm}$ in diameter were used throughout the experiment. Paper discs were sterilized in an autoclave and dried at $100^{\circ} \mathrm{C}$ in an oven. Then the discs were soaked with test chemicals at the rate of $50 \mu \mathrm{g}$ (dry weight) per disc for antibacterial analysis. For pour plate technique, one drop of bacterial suspension was taken in a sterile petri dish and approximately $20 \mathrm{ml}$ of melted sterile nutrient agar (NA) $\left(\sim 45^{\circ} \mathrm{C}\right)$ was poured into the plate, and then mixed thoroughly with the direction of clockwise and anticlockwise. After solidification of the seeded NA medium, paper disc after soaking with test chemicals $\left(2 \%\right.$ in $\left.\mathrm{CHCl}_{3}\right)$ were placed at the centre of the inoculated petri dish. A control plate was also maintained in each case with chloroform. Firstly, the plates were kept for 4 hrs. at low temperature $\left(4^{\circ} \mathrm{C}\right)$ and the test chemicals diffused from disc to the surrounding medium by this time. The plates were then incubated at $(35 \pm 2)^{\circ} \mathrm{C}$ for growth of test organisms and were observed at $24 \mathrm{hrs}$. intervals for two days. The activity was expressed in terms of inhibition zone diameter in mm. Each experiment was repeated thrice. The standard antibiotic Ampicillin from FISONS Ltd. (Bangladesh) was used as a positive control and compared with tested chemicals under identical conditions.

\section{Antifungal efficacy test}

The in vitro antifungal functionality tests of the synthesized chemicals were tested by mycelial growth test ${ }^{32}$. Required amount of medium was taken in a conical flask separately and was sterilized in autoclave. After autoclaving, weighted amount of test chemicals (2\%) was added to the sterilized medium in 
conical flask at the point of pouring to obtain the desired concentration. The flask was shaken thoroughly to mix the chemical with the medium homogeneously before pouring. The medium with definite concentration (2\%) of chemical was poured at the rate of $10 \mu \mathrm{l}$ in sterilized glass Petri dishes individually. Proper control was maintained separately with sterilized PDA (potato dextrose agar) medium without chemicals and three replications were prepared for each treatment. After solidification of medium, the fungal inoculums $(5 \mathrm{~mm}$ approximately) were placed at the centre of each Petri dish in an inverted position. All the plates were inoculated at room temperature on the laboratory desk for five days. The linear growth of fungal colony was measured in two directions at right angle to each other after five days of incubation and average of three replicates was taken as the diameter of a colony in $\mathrm{mm}$. The percentage inhibition of mycelial growth of test fungi was calculated as follow:

$$
I=\left\{\frac{C-T}{C}\right\} \times 100
$$

Where, $\mathrm{I}=$ percentage of inhibition, $\mathrm{C}=$ diameter of the fungal colony in control, $\mathrm{T}=$ diameter of the fungal colony in treatment. The antifungal results were compared with that of the standard antibiotic, Nystatin $(100 \mu \mathrm{g} \mathrm{dw}$./disc, BEXIMCO Pharm. Bangladesh Ltd.).

Table 2. Molecular formula of the test compounds.

\begin{tabular}{|c|c|c|}
\hline Compounds & Name of the tested compounds & Molecular formula \\
\hline 2 & $5 '-0$-0ctanoyluridine & $\mathrm{C}_{17} \mathrm{H}_{26} \mathrm{O}_{7} \mathrm{~N}_{2}$ \\
\hline 3 & $5^{\prime}-0$-0ctanoyl-2',3'-di-0-pentanoyluridine & $\mathrm{C}_{27} \mathrm{H}_{42} \mathrm{O}_{9} \mathrm{~N}_{2}$ \\
\hline 4 & $2^{\prime}, 3^{\prime}$-Di-0-hexanoyl-5'-0-octanoyluridine & $\mathrm{C}_{29} \mathrm{H}_{46} \mathrm{O}_{9} \mathrm{~N}_{2}$ \\
\hline 5 & $2^{\prime}, 3^{\prime}$-Di-0-decanoyl-5'-0-octanoyluridine & $\mathrm{C}_{37} \mathrm{H}_{62} \mathrm{O}_{9} \mathrm{~N}_{2}$ \\
\hline 6 & $2^{\prime}, 3^{\prime}$-Di-0-lauroyl-5'-0-octanoyluridine & $\mathrm{C}_{41} \mathrm{H}_{70} \mathrm{O}_{9} \mathrm{~N}_{2}$ \\
\hline 7 & $2^{\prime}, 3^{\prime}$-Di-0-myristoyl-5'-0-octanoyluridine & $\mathrm{C}_{45} \mathrm{H}_{78} \mathrm{O}_{9} \mathrm{~N}_{2}$ \\
\hline 8 & $5^{\prime}$-0-0ctanoyl-2',3'-di-0-palmitoyluridine & $\mathrm{C}_{49} \mathrm{H}_{86} \mathrm{O}_{9} \mathrm{~N}_{2}$ \\
\hline 9 & $5^{\prime}-0$-0ctanoyl-2',3'-di-0-pivaloyluridine & $\mathrm{C}_{27} \mathrm{H}_{42} \mathrm{O}_{9} \mathrm{~N}_{2}$ \\
\hline
\end{tabular}




\begin{tabular}{|c|c|c|}
\hline 10 & 2',3'-Di-O-methanesulphonyl-5'-O-octanoyluridine $^{\prime}$ & $\mathrm{C}_{19} \mathrm{H}_{30} \mathrm{O}_{11} \mathrm{~N}_{2} \mathrm{~S}_{2}$ \\
\hline 11 & 2',3'-Di-O-benzenesulphonyl-5'-O-octanoyluridine & $\mathrm{C}_{29} \mathrm{H}_{34} \mathrm{O}_{11} \mathrm{~N}_{2} \mathrm{~S}_{2}$ \\
\hline 12 & 2',3'-Di-O-(2-bromobenzoyl)-5'-O-octanoyluridine $^{\prime}$ & $\mathrm{C}_{31} \mathrm{H}_{32} \mathrm{O}_{9} \mathrm{~N}_{2} \mathrm{Br}_{2}$ \\
\hline 13 & 2',3'-Di-O-(4-chlorobenzoyl)-5'-O-octanoyluridine $^{\prime}$ & $\mathrm{C}_{31} \mathrm{H}_{32} \mathrm{O}_{9} \mathrm{~N}_{2} \mathrm{Cl}_{2}$ \\
\hline
\end{tabular}

\section{RESULTS AND DISCUSSION}

\section{Synthesis and characterization}

In the present investigation, we carried out selective octanoylation of of uridine (1) with octanoyl chloride using the direct acylation method (Scheme 1-2 \& Table $3 \& 4$ ). A series of derivatives of the resulting acylation products were prepared in order to gather supportive evidences for structure elucidation and also to obtain newer derivatives of synthetic and biological importance.

Our initial effort was to carry out selective acylation of uridine (1) with unimolecular amount of non-traditional acylating agent octanoyl chloride in dry pyridine at $-5^{\circ} \mathrm{C}$. Conventional work-up procedure, followed by removal of solvent and silica gel column chromatographic purification, we obtained the octanoyl derivative (2). This compound (2) was sufficiently pure for use in the next reactions. The IR spectrum of this compound showed the following characteristic peaks: 1728 (-CO) and 3358-3520 $\mathrm{cm}^{-1}$ (br -OH stretching). In its ${ }^{1} \mathrm{H}-\mathrm{NMR}$ spectrum, two two-proton multiplets at $\left.\delta 2.34 \mathrm{CH}_{3}\left(\mathrm{CH}_{2}\right)_{5} \mathrm{CH}_{2} \mathrm{CO}-\right\}$ and $1.61\left\{\mathrm{CH}_{3}\left(\mathrm{CH}_{2}\right)_{4} \mathrm{CH}_{2} \mathrm{CH}_{2} \mathrm{CO}-\right\}$, an eight-proton multiplet at $\delta 1.26$ $\left\{\mathrm{CH}_{3}\left(\mathrm{CH}_{2}\right)_{4}\left(\mathrm{CH}_{2}\right)_{2} \mathrm{CO}-\right\}$ and a three-proton multiplet at $\delta$ o.87 $\left\{\mathrm{CH}_{3}\left(\mathrm{CH}_{2}\right)_{6} \mathrm{CO}-\right\}$ were due to the one octanoyl group, thereby suggesting the introduction of one octanoyl group in the molecule. The downfield shift of $\mathrm{C}-5^{\prime}$ proton to $\delta 5.81$ (as dd, $\mathrm{J}=2.1$ and $12.1 \mathrm{~Hz}, 5^{/ \mathrm{a}}$ ) and 5.77 (as dd, $\mathrm{J}=2.2$ and $12.3 \mathrm{~Hz}, 5^{/ \mathrm{b}}$ ) from their usual values ${ }^{33}$ in the precursor compound (1) and the resonances of other protons in their anticipated positions, showed the presence of the octanoyl group at position $5^{\prime}$. The formation of $5^{/}-O$-octanoyluridine (2) might be due to higher reactivity of the sterically less hindered primary hydroxyl group of the ribose moiety of uridine (1). By complete analysis of the FTIR, ${ }^{1} \mathrm{H}-\mathrm{NMR}$ and elemental data, the structure of this compound was assigned as $5^{/}-\mathrm{O}-$ octanoyluridine (2). 
<smiles>O=c1ccn(C2OC(CO)C(O)C2O)c(=O)[nH]1</smiles>

Uridine (1)

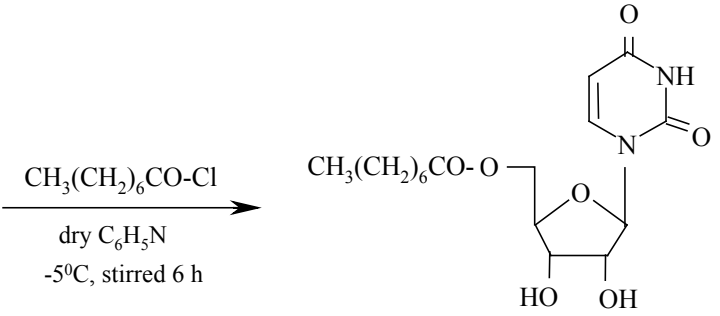

5/-O-acylated uridine (2) (82\%)

Scheme 1. Synthesis of 5'-0-octanoyluridine (Compound 2).<smiles>CC(=O)OCC1OC2OC1C(n1ccc(=O)[nH]c1=O)C2O</smiles>

5'-O-acylated uridine (2)

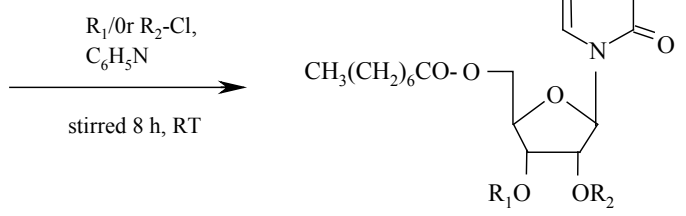

Acylated uridine derivatives (3-13)

Scheme 2. Synthesis of 2/,3/-di-0-acylated 5'-0-octanoyluridine esters (Compounds 3-13).

Table 3. Synthesized of uridine derivatives (Compounds 2-13)

\begin{tabular}{|c|c|c|c|}
\hline Compounds & $R_{1}=R_{2}$ & Compounds & $R_{1}=R_{2}$ \\
\hline 2 & $\mathrm{H}$ & 8 & $\mathrm{CH}_{3}\left(\mathrm{CH}_{2}\right)_{14} \mathrm{CO}-$ \\
\hline 3 & $\mathrm{CH}_{3}\left(\mathrm{CH}_{2}\right)_{3} \mathrm{CO}-$ & 9 & $\left(\mathrm{CH}_{3}\right)_{3} \mathrm{CCO}-$ \\
\hline 4 & $\mathrm{CH}_{3}\left(\mathrm{CH}_{2}\right)_{4} \mathrm{CO}-$ & 10 & $\mathrm{CH}_{3} \mathrm{SO}_{2-}^{-}$ \\
\hline 5 & $\mathrm{CH}_{3}\left(\mathrm{CH}_{2}\right)_{8} \mathrm{CO}-$ & 11 & $\mathrm{C}_{6} \mathrm{H}_{5} \mathrm{SO}_{2}^{-}$ \\
\hline 6 & $\mathrm{CH}_{3}\left(\mathrm{CH}_{2}\right)_{10} \mathrm{CO}-$ & 12 & $2-\mathrm{Br} . \mathrm{C}_{6} \mathrm{H}_{4} \mathrm{CO}-$ \\
\hline 7 & $\mathrm{CH}_{3}\left(\mathrm{CH}_{2}\right)_{12} \mathrm{CO}-$ & 13 & 4-Cl. $\mathrm{C}_{6} \mathrm{H}_{4} \mathrm{CO}-$ \\
\hline
\end{tabular}


The diol (2) was then allowed to react with pentanoyl chloride in dry $\mathrm{C}_{6} \mathrm{H}_{5} \mathrm{~N}$ at freezing temperature. Usual work-up procedure provided the $2^{\prime}, 3^{/}$-di$O$-pentanoyl derivative (3). The FTIR spectrum of compound $\mathbf{3}$ showed absorption band at $1758 \mathrm{~cm}^{-1}$ for carbonyl stretching. In the ${ }^{1} \mathrm{H}-\mathrm{NMR}$ spectrum of compound 3 , the resonance peaks three four-proton multiplets at $\delta 2.35\left\{2 \times \mathrm{CH}_{3}\left(\mathrm{CH}_{2}\right)_{2} \mathrm{CH}_{2} \mathrm{CO}-\right\}, \delta 1.61\left\{2 \times \mathrm{CH}_{3} \mathrm{CH}_{2} \mathrm{CH}_{2} \mathrm{CH}_{2} \mathrm{CO}-\right\}$ and $\delta 1.38\left\{2 \times \mathrm{CH}_{3} \mathrm{CH}_{2}\left(\mathrm{CH}_{2}\right)_{2} \mathrm{CO}\right\}$ and one six-proton multiplet at $\delta 0.88$ $\left\{2 \times \mathrm{CH}_{3}\left(\mathrm{CH}_{2}\right)_{3} \mathrm{CO}-\right\}$ correspond to the presence of two pentanoyl groups in the molecule. The deshielding of $\mathrm{H}-2^{\prime}$, and $\mathrm{H}-3^{\prime}$ protons to $\delta 4.52$ (as d, $\mathrm{J}=5.2 \mathrm{~Hz}$ ) and $\delta 4.33$ (as dd, $\mathrm{J}=7.7$ and $5.6 \mathrm{~Hz}$ ) from their usual values ( 4.00 ppm), showed the attachment of the two pentanoyl groups at positions $2^{/}$and $3^{\prime}$. The mass spectra of the compound $\mathbf{3}$ showed a molecular ion peak at $m / z[\mathrm{M}+\mathrm{H}]^{+}$ 539.60 which is corresponding to a molecular formula $\mathrm{C}_{27} \mathrm{H}_{42} \mathrm{O}_{9} \mathrm{~N}_{2}$. Complete analysis of the FTIR, ${ }^{1} \mathrm{H}-\mathrm{NMR}$, mass spectra and elemental data, the structure of this compound was assigned as $5^{/}-O$-octanoyl-2/, $3^{/}$-di-O-pentanoyluridine (3).

Further support for the structure accorded to the octanoyl derivative (2) was obtained by preparation and identification of the dihexanoate (4). The FTIR spectrum of this compound 4 showed absorption band at $1730 \mathrm{~cm}^{-1}(\mathrm{C}=\mathrm{O})$, thereby suggesting the presence of carbonyl group. In its ${ }^{1} \mathrm{H}-\mathrm{NMR}$ spectrum provided two four-proton multiplets at $\delta 2.35\left\{2 \times \mathrm{CH}_{3}\left(\mathrm{CH}_{2}\right)_{3} \mathrm{CH}_{2} \mathrm{CO}-\right\}$, and $\delta 1.62\left\{2 \times \mathrm{CH}_{3}\left(\mathrm{CH}_{2}\right)_{2} \mathrm{CH}_{2} \mathrm{CH}_{2} \mathrm{CO}-\right\}$, an eight-proton multiplet at $\delta$ $1.27\left\{2 \times \mathrm{CH}_{3}\left(\mathrm{CH}_{2}\right)_{2} \mathrm{CH}_{2} \mathrm{CH}_{2} \mathrm{CO}-\right\}$ and one six-proton multiplet at $\delta 0.85$ $\left\{2 \times \mathrm{CH}_{3}\left(\mathrm{CH}_{2}\right)_{4} \mathrm{CO}-\right\}$ indicating the presence of two hexanoyl groups in the compound. The resonance for $\mathrm{H}-2^{\prime}$, and $\mathrm{H}-3^{\prime}$ protons appeared at $\delta 4.95$ (as $\mathrm{d}, \mathrm{J}=$ $5.2 \mathrm{~Hz}$ ) and $\delta 4.39$ (as dd, $J=7.8$ and $5.6 \mathrm{~Hz}$ ) which shifted downfield from their precursor compound (2) suggesting the attachment of the hexanoyl groups at positions $2^{/}$and $3^{\prime}$. Mass spectra of the compound 4 showed a molecular ion peak at $m / z[\mathrm{M}+\mathrm{H}]^{+} 567.50$ which is corresponding to a molecular formula $\mathrm{C}_{29} \mathrm{H}_{46} \mathrm{O}_{9} \mathrm{~N}_{2}$. The rest of the FTIR, ${ }^{1} \mathrm{H}-\mathrm{NMR}$, mass spectra and elemental data was in complete agreement with the structure accorded to the hexanoyl derivative as, $2^{/}, 3^{/}$-di-O-hexanoyl-5/-O-octanoyluridine (4). 
Table 4. Physicochemical properties of the synthesized of uridine derivatives (2-13).

\begin{tabular}{|c|c|c|c|c|}
\hline Compounds & RT (h) & $R_{f}$ value & (\%) Yield & State \\
\hline 2 & 6.0 & 0.50 & 82 & semi solid \\
\hline 3 & 5.5 & 0.51 & 91 & pasty mass \\
\hline 4 & 6.0 & 0.52 & 88 & thick syrup \\
\hline 5 & 6.0 & 0.50 & 92 & pasty mass \\
\hline 6 & 6.0 & 0.51 & 91 & needles, m.p. $49-50^{\circ} \mathrm{C}$ \\
\hline 7 & 6.5 & 0.52 & 86 & needles, m.p. $64-66^{\circ} \mathrm{C}$ \\
\hline 8 & 6.0 & 0.55 & 76 & needles, m.p. $65-67^{\circ} \mathrm{C}$ \\
\hline 9 & 5.5 & 0.51 & 89 & semi solid \\
\hline 10 & 6.0 & 0.51 & 72 & syrupy \\
\hline 11 & 6.5 & 0.50 & 76 & thick syrupy \\
\hline 12 & 6.0 & 0.52 & 93 & pasty mass \\
\hline 13 & 5.5 & 0.50 & 89 & thick syrupy \\
\hline
\end{tabular}

In addition, confirmation of the structure accorded to compound (2) was achieved by its conversion to and identification by ${ }^{1} \mathrm{H}-\mathrm{NMR}$ of its di-Odecanoyl derivative (5). The ${ }^{1} \mathrm{H}-\mathrm{NMR}$ spectrum of compound 5 provided the following characteristic peaks: two four-proton multiplets at $\delta 2.36$ $\left\{2 \times \mathrm{CH}_{3}\left(\mathrm{CH}_{2}\right)_{7} \mathrm{CH}_{2} \mathrm{CO}-\right\}$ and $1.60\left\{2 \times \mathrm{CH}_{3}\left(\mathrm{CH}_{2}\right)_{6} \mathrm{CH}_{2} \mathrm{CH}_{2} \mathrm{CO}-\right\}$, a twenty fourproton multiplet at $\delta 1.26\left\{2 \times \mathrm{CH}_{3}\left(\mathrm{CH}_{2}\right)_{6}\left(\mathrm{CH}_{2}\right)_{2} \mathrm{CO}-\right\}$ and a six-proton multiplet at $\delta 0.85\left\{2 \times \mathrm{CH}_{3}\left(\mathrm{CH}_{2}\right)_{8} \mathrm{CO}-\right\}$ indicating the introduction of two decanoyl groups to the molecule. In the showed a molecular ion peak at $m / z[M+H]^{+}$ 680.29 which is corresponding to a molecular formula $\mathrm{C}_{37} \mathrm{H}_{62} \mathrm{O}_{9} \mathrm{~N}_{2}$. On the basis of complete analysis of the FTIR, ${ }^{1} \mathrm{H}-\mathrm{NMR}$, mass spectra and elemental data, the structure of this compound was accorded as $2^{\prime}, 3^{\prime}$-di-O-decanoyl- $5^{\prime-}$ O-octanoyluridine (5).

Next effort was to carry out lauroylation of the octanoate (2) and provided the lauroyl derivative (6). The FTIR spectrum of the compound (6) displayed 
absorption band at $1758 \mathrm{~cm}^{-1}$ due to carbonyl stretching. It's ${ }^{1} \mathrm{H}-\mathrm{NMR}$ spectrum exhibited two four-proton multiplets at $2.37\left\{2 \times \mathrm{CH}_{3}\left(\mathrm{CH}_{2}\right)_{9} \mathrm{CH}_{2} \mathrm{CO}-\right\}$ and $\delta 1.59\left\{2 \times \mathrm{CH}_{3}\left(\mathrm{CH}_{2}\right)_{8} \mathrm{CH}_{2} \mathrm{CH}_{2} \mathrm{CO}-\right\}$ a thirty two-proton multiplet at $\delta 1.21\left\{2 \times \mathrm{CH}_{3}\left(\mathrm{CH}_{2}\right)_{8}\left(\mathrm{CH}_{2}\right)_{2} \mathrm{CO}-\right\}$ and a six-proton multiplet at $\delta 0.88$ $\left\{2 \times \mathrm{CH}_{3}\left(\mathrm{CH}_{2}\right)_{10} \mathrm{CO}-\right\}$, therefore, suggesting the presence of two lauroyl groups in the compound (6). Complete analysis of the FTIR, ${ }^{1} \mathrm{H}-\mathrm{NMR}$ and elemental data was in complete agreement with the structure established as $2^{\prime}, 3^{\prime}-\mathrm{di}-\mathrm{O}$ lauroyl-5/-O-octanoyluridine (6). Myristoylation of compound (2) provided the FTIR spectrum, absorption band at $1736 \mathrm{~cm}^{-1}$ corresponded to carbonyl group. The presence of four-proton multiplet at $\delta 2.35\left\{2 \times \mathrm{CH}_{3}\left(\mathrm{CH}_{2}\right)_{11} \mathrm{CH}_{2} \mathrm{CO}-\right\}$, a forty-four-proton multiplet at $\delta 1.26\left\{2 \times \mathrm{CH}_{3}\left(\mathrm{CH}_{2}\right)_{11} \mathrm{CH}_{2} \mathrm{CO}-\right\}$ and a six-proton multiplet at $\delta \mathrm{o} .88\left\{2 \times \mathrm{CH}_{3}\left(\mathrm{CH}_{2}\right)_{12} \mathrm{CO}-\right\}$, in its ${ }^{1} \mathrm{H}-\mathrm{NMR}$ spectrum were due to two myristoyl groups in the molecule. Complete analysis of this compound was in complete agreement with the structure accorded to it as the structure of the myristoate was assigned as $2^{/}, 3 /$-di-O-myristoyl- $5^{/}-O$-octanoyluridine (7).

The palmitoyl (8) was ascertained by observing the following resonance peaks: $\delta 2.36\left\{4 \mathrm{H}, \mathrm{m}, 2 \times \mathrm{CH}_{3}\left(\mathrm{CH}_{2}\right)_{13} \mathrm{CH}_{2} \mathrm{CO}-\right\}, \delta 1.24\left\{52 \mathrm{H}, \mathrm{m}, 2 \times \mathrm{CH}_{3}\left(\mathrm{CH}_{2}\right)_{13} \mathrm{CH}_{2} \mathrm{CO}-\right\}$ and $\delta 0.88\left\{6 \mathrm{H}, \mathrm{m}, 2 \times \mathrm{CH}_{3}\left(\mathrm{CH}_{2}\right)_{14} \mathrm{CO}-\right\}$. The introduction of the palmitoyl groups at position $2^{\prime}$ and $3^{\prime}$ were indicated by appearance of $\mathrm{H}-2^{\prime}$ and $\mathrm{H}-3^{\prime}$ resonance peaks at $\delta 5.02$ and $\delta 4.87$, deshielded considerably from its precursor diol (2). The rest of the FTIR, ${ }^{1} \mathrm{H}-\mathrm{NMR}$ and elemental analysis was compatible with structure assigned as $5^{\prime}-O$-octanoyl-2/, $3^{\prime}$-di-O-palmitoyluridine (8). The structure of the octanoyl derivative (2) was further supported by its conversion to the pivaloyl derivative (9). The FTIR spectrum showed carbonyl stretching band at $1740 \mathrm{~cm}^{-1}$. In its ${ }^{1} \mathrm{H}-\mathrm{NMR}$ spectrum, a characteristic eighteen-proton singlet at $\delta 1.21\left\{2 \times\left(\mathrm{CH}_{3}\right)_{3} \mathrm{CCO}-\right\}$ was due to the methyl protons of two pivaloyl groups. By analyzing the FTIR, ${ }^{1} \mathrm{H}-\mathrm{NMR}$ and elemental data completely, the structure of the dipivaloate was established as $5^{/}$-O-octanoyl$2^{2}, 3^{\prime}$-di-O-pivaloyluridine (9). Next, we methanesulfonoate (10) was obtained in $83 \%$ yield and the FTIR spectrum provided the absorption bands at 1765 $\mathrm{cm}^{-1}$ due to $\mathrm{C}=\mathrm{O}$ stretching and $1365 \mathrm{~cm}^{-1}$ for $-\mathrm{SO}_{2}$ stretching. The ${ }^{1} \mathrm{H}-\mathrm{NMR}$ spectrum, of this compound showed the following characteristic peaks: two three-proton singlets at $\delta 3.10$ and $\delta 3.05\left(2 \times \mathrm{CH}_{3} \mathrm{SO}_{2}{ }^{-}\right)$ascertaining the presence of two methanesulfonyl groups in the molecule. Complete analysis of the FTIR, ${ }^{1} \mathrm{H}-\mathrm{NMR}$ and elemental data led us to establish its structure as $2^{\prime}, 3^{\prime}$-di$O$-methanesulfonyl-5/-O-octanoyluridine (10).

The $2^{\prime}, 3^{\prime}$-di-O-benzenesulfonyl derivative (11) was also prepared and in its ${ }^{1} \mathrm{H}$ NMR spectrum, the characteristic peaks at $\delta 7.90(4 \mathrm{H}, \mathrm{m}), \delta 7.56(2 \mathrm{H}, \mathrm{m})$ and $\delta 7.41(4 \mathrm{H}, \mathrm{m})$ corresponded the aromatic protons of two phenyl groups in 
the compound. The downfield shift of $\mathrm{H}-2^{/}$proton to $\delta 4.76$ and $\mathrm{H}-3^{\prime}$ proton to $\delta 4.56$ from their precursor diol (2) values, ascertained the attachment of benzenesulfonyl groups at $2^{\prime}$ and $3^{\prime}$ positions. The rest of the FTIR, ${ }^{1} \mathrm{H}-\mathrm{NMR}$ and elemental analysis was in complete agreement with the structure accorded to the benzenesulfonyl derivative as, $2^{\prime}, 3^{\prime}$-di-O-benzenesulfonyl-5/-O-octanoyluridine (11). Further, the confirmation of the structure of the $5 /$-O-octanoyl derivative (2) was achieved by its transformation into and identification of the di-O-(2-bromobenzoyl) (12) and di-O-(4-chlorobenzoyl) (13) derivatives.

Thus, selective octanoylation of uridine (1) was successfully carried out using the direct acylation method. A single, monosubstitution product was isolated pure in each case in reasonably high yields. The octanoyl derivative was further transformed into its different acyl derivatives. These transformations were conducted in order to gather supportive evidences for elucidating structures of the parent acylation products and also to obtain new products of synthetic and biological importance. All these newly synthesized products (Table 3) may be employed as important precursors for the modification of the uridine (1) molecule at different positions.

\section{Screening of microbial efficacy}

From the experimental results obtained by using a number of selected human pathogenic bacteria (as shown in Figure 2, 3 \& 5) were found that selectively acylated uridine derivatives $\mathbf{1 0}, \mathbf{1 1}$ and $\mathbf{1 3}$ showed good inhibition against Gram-positive bacteria while compounds 10 and $\mathbf{1 3}$ were also very active against Gram-negative bacteria. We also observed that some compounds such as $\mathbf{1 0}$ and $\mathbf{1 3}$ are highly active against both the Gram-positive and Gram-negative organisms. So, these compounds may be targeted for future studies for their usage as broad spectrum antibiotics. In general, it has been observed that antibacterial results of the selectively acylated uridine derivatives obtained by using various acylating agents follow the order for Gram-positive organisms: $10>13>9>11=3>4>5>12=7$ and Gram-negative bacteria follow the order: $10>13=11>6=4>5>9$. 


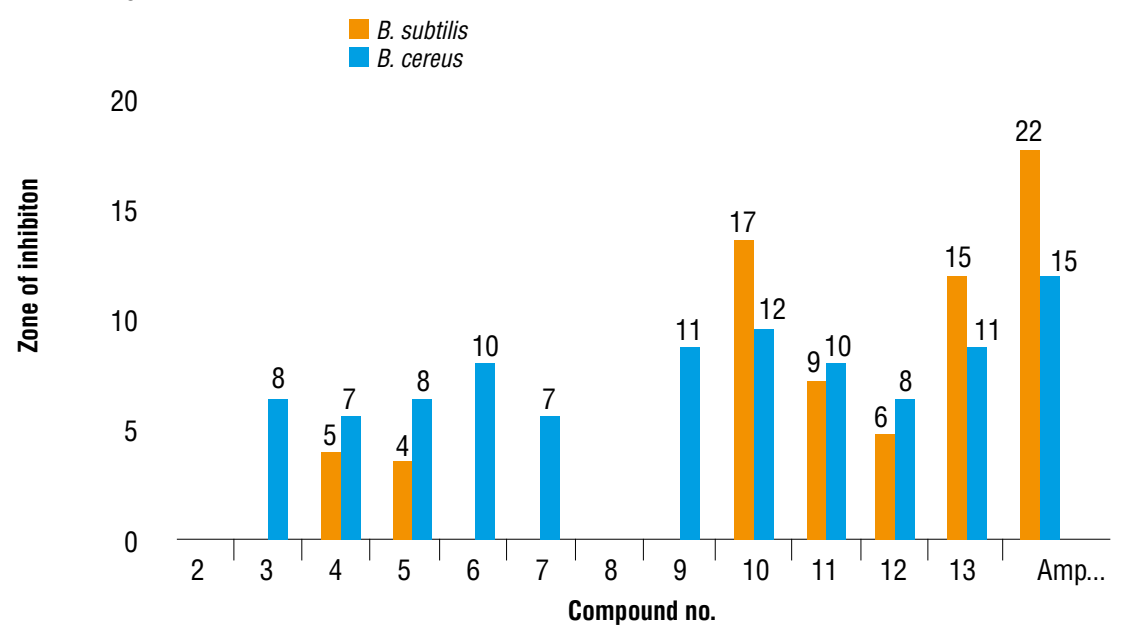

Figure 2. Zone of inhibition observed against Gram-positive bacteria by the test compounds.

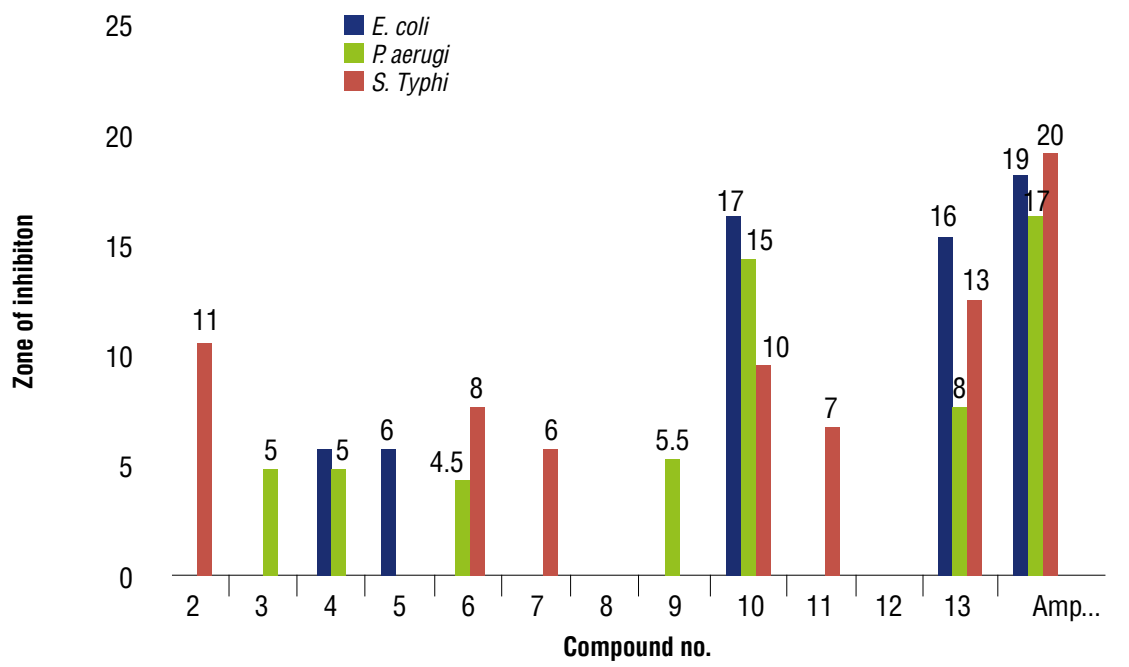

Figure 3. Zone of inhibition observed against Gram-negative bacteria by the test compounds.

From this study we found that among the acylated products, compound $\mathbf{1 0}$ showed effective activities (17 mm) against both B. subtilis \& E. coli and compounds $13(16 \mathrm{~mm})$ and $10(15 \mathrm{~mm})$ showed high activity against the $E$. coli and $P$. aeruginosa microorganisms, respectively. Some of the tested chemicals showed moderate to marked inhibition against the bacterial pathogens employed. It was also found that some tested chemicals were unable to show any 
inhibition at all against the bacterial pathogens employed. It was also observed that the uridine derivatives were found comparatively more effective against Gram-positive bacteria than that of Gram-negative bacteria.

The results obtained from the present investigation of antifungal studies mentioned in Figure 4 and 6 clearly demonstrate that compounds 5 showed the highest inhibition (60.0\%) against the Rhizopers nigricans. Excellent inhibition was observed in case of compound $\mathbf{1 0}$ (55.0\%) in which the percent inhibi tion is very close to the standard antibiotic Nystatin against Aspergillus niger. Compounds 4 (50.0\%) and $\mathbf{1 3}$ (50.0\%) showed the good inhibition against the Aspergillus niger and Rhizopers nigricans, respectively. However, most of the compounds showed to be less active or toxic to the selected plant pathogens as compared to the standard antibiotic (Nystatin).

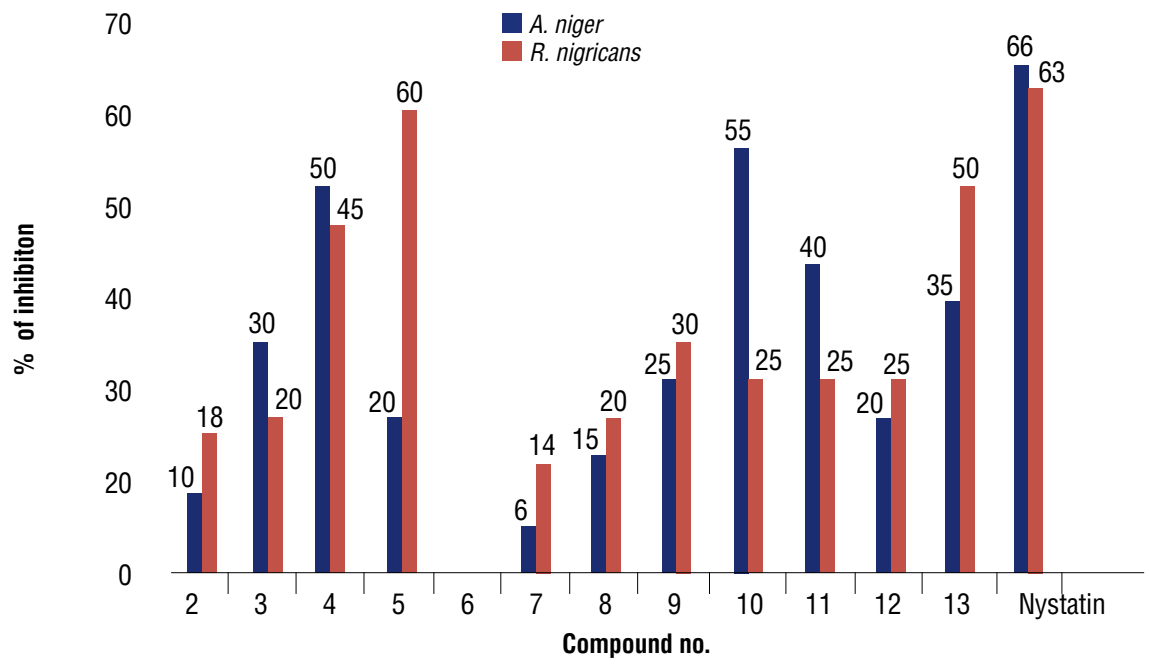

Figure 4. The percentage inhibition of mycelial growth of test fungi by the test compounds. 

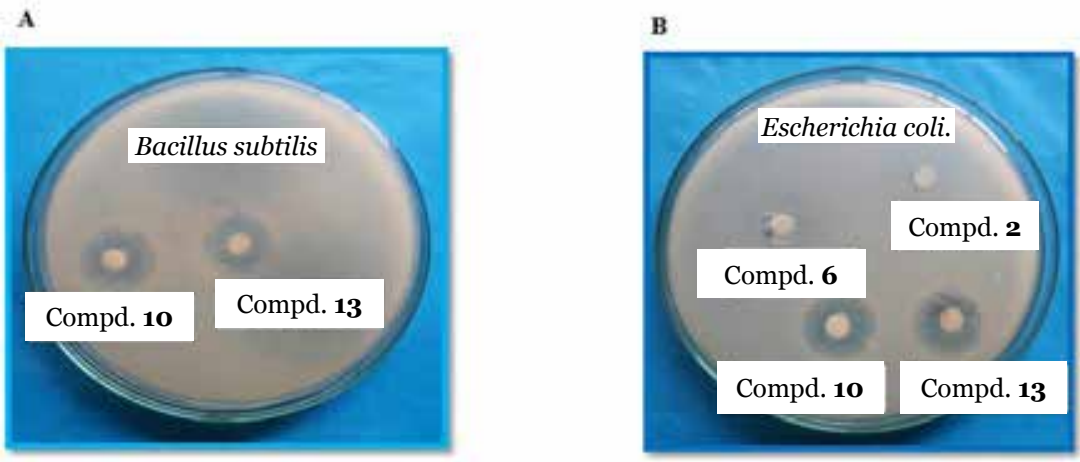

Figure 5. A. Zone of inhibition of the compounds 10 and 13 against $B$. subtilis and B. Zone of inhibition of the compounds 2, 6, 10 and 13 against $E$. coli.
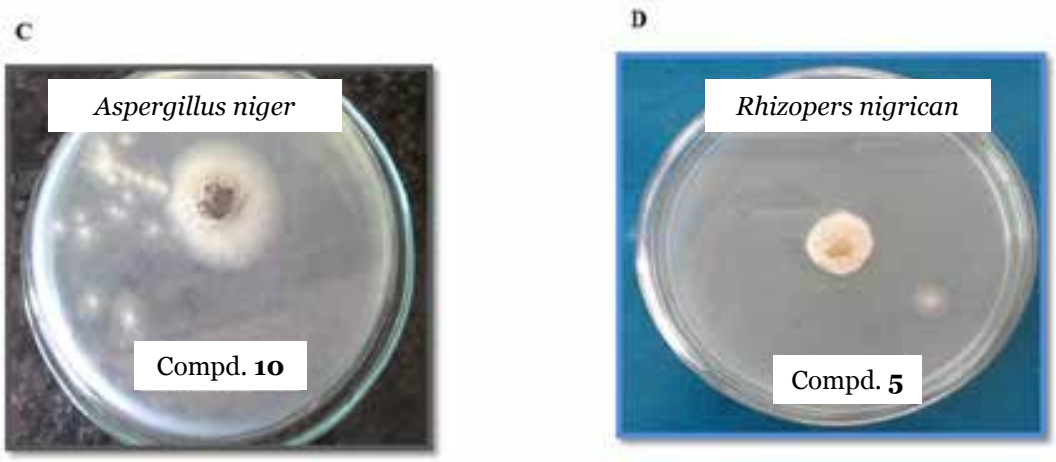

Figure 6. C. The percentage inhibition mycelial growth inhibition of the compound 10 against A. niger and $\mathrm{D}$. The percentage inhibition mycelial growth inhibition of the compound 5 against $R$. nigricans.

So, it was found that the newly synthesized and reported compounds $\mathbf{5}$ and 10 were very much effective against both fungal strains. These antimicrobial efficacies of our tested compounds were in accordance with the results we observed before ${ }^{34,35}$. The brine shrimp lethality assay is considered a useful tool for assessment of toxicity. The cytotoxic activity of the acylated derivatives of uridine (Scheme 1, 2, Table 1) in the brine shrimp lethality bioassay showed different rate mortality with different concentrations. It is expected that this piece of work employing uridine derivatives as test compounds will open the scope for further work on the development of pesticides and medicines sectors. 


\section{CONCLUSION}

The synthesized uridine derivatives have shown promising antibacterial and antifungal activities. Out of twelve active compounds, three of them $(\mathbf{5}, \mathbf{1 0}$ and 15) have shown very good antimicrobial inhibiting activity. However, these three compounds have also shown significant cytotoxic activity against brine shrimp lethality assay. Therefore, it is expected that the newly acylated uridine derivatives might show potential antiviral, antidiabetic, anticancer and antiinflammatory activities.

\section{ACKNOWLEDGEMENT}

The authors are thankful to the Research \& Publication Cell, University of Chittagong for providing financial assistance to perform the present research work.

\section{REFERENCES}

1. Carlezon, J. W. A.; Mague, S. D.; Parow, A. M.; Stoll, A. L.; Cohen, B. M.; Renshaw, P. F. Antidepressant-like Effects of Uridine and Omega-3 Fatty Acids are Potentiated by Combined Treatment in Rats. Biol. Psychiatry. 2005, 57, 343-350

2. Jonas, D. A.; Elmadfa, I.; Engel, K. H.; Heller, K. J.; Kozianowski, G.; Konig, A.; Muller, D.; Narbonne, J. F.; Wackemagel, W.; Kleiner, J. Safety Considerations of DNA in Food. Annals Nutr. Metabol. 2001, 45, 235-254.

3. Macdonald, G.; Assef, R.; Guiffre, A.; Lo, E. Vasoconstrictor Effects of Uridine and its Nucleotides and their Inhibition by Adenosine. Clin. Exp. Pharmacol. Physiol. 1984, 11, 381384 .

4. Siggins, G. R.; Gruol, D. L.; Padjen, A. L.; Formans, D. S. In: Iontophoresis and Transmitter Mechanisms in the Mammalian Central Nervous System. Ryall RW, Kelly JS. Editors, Elsevier/North-Holland, 1978, 453-455.

5. Groeningen, C. J.; Leyva, A.; Kraal, I.; Peters, G. J.; Pinedo, H. M. Clinical and Pharmacokinetic Studies of Prolonged Administration of High-dose Uridine Intended for Rescue from 5-FU Toxicity. Cancer Treat Rep. 1986, 7o, 745-750.

6. Morris, D. J. Adverse Effects and Drug Interactions of Clinical Importance with Antiviral Drugs. Drug Saf. 1994, 1O, 281-291.

7. De Clercq, E. A 40-Year Journey in Search of Selective Antiviral Chemotherapy. Annu. Rev. Pharmacol. Toxicol. 2011, 51, 1-24.

8. De Clercq, E.; Holy, A. Acyclic Nucleoside Phosphonates: a Key Class of Antiviral Drugs. Nat. Rev. Drug Discovery. 2005, 4, 928-940.

9. Ri, M.; Tashiro, E.; Oikawa, D.; Shinjo, S.; Tokuda, M.; Yokouchi, Y, et al. Identification of Toyocamycin, an Agent Cytotoxic for Multiple Myeloma Cells, as a Potent Inhibitor of ER Stress-Induced XBP1 mRNA Splicing. Blood Cancer J. 2012, 2, e79.

10. Damaraju, V. L.; Damaraju, S.; Young, J. D.; Baldwin, S. A.; Mackey, J.; Sawyer, M. B.; 
Cass, C. E. Nucleoside Anticancer Drugs: the Role of Nucleoside Transporters in Resistance to Cancer Chemotherapy. Oncogene. 2003, 22, 7524-7536.

11. Najera, I. Resistance to HCV Nucleoside Analogue Inhibitors of Hepatitis C Virus RNADependent RNA Polymerase. Curr. Opin. Virol. 2013, 3, 508-513.

12. Jordheim, L. P.; Durantel, D.; Zoulim, F.; Dumontet, C. Advances in the Development of Nucleoside and Nucleotide Analogues for Cancer and Viral Diseases. Nat. Rev. Drug Discovery. 2013, 12, 447-464.

13. Tsuda, Y.; Haque, E. Regioselective Introduction of p-Coumaroyl Group to a-LArabinopyranosides. Total Synthesis of Inundoside-G and Inundoside-D1. Chem. Pharm. Bull. 1983, 31, 1437-1439.

14. Itoh, M.; Hagiwara, D.; Notani, J. A Simple and Mild Esterification Method for Carboxylic Acids Using Sulfonate-type Coupling Reagents. Synthesis. 1975, 7, 456-458.

15. Kondo, Y. Selective Benzoylation of Methyl $\alpha$ - and $\beta$-D-Xylopyranoside. Carbohydr. Res. 1982, 107, 303-311.

16. Sugihara, J. M. Relative Reactivities of Hydroxyl Groups of Carbohydrates. Adv. Carbohydr. Chem. 1953, 8, 1-44.

17. Wagner, D.; Verheyden, J. P. H.; Moffatt, J. G. Preparation and Synthetic Utility of some Organotin Derivatives of Nucleosides. J. Org. Chem. 1974, 39, 24-30.

18. Williams, J. M.; Richardson, A. C. Selective Acylation of Pyranosides-I. Benzoylation of methyl $\alpha$-D-glycopyranosides of Mannose, Glucose and Galactose. Tetrahedron. 1967, 23, 1369-1378.

19. Kim, S.; Chang, H.; Kim, W. J. Regioselective Acylation of some Glycopyranoside Derivatives. J. Org. Chem. 1985, 5O, 1751-1752.

20. Kabir, A. K. M. S.; Dutta, P.; Anwar, M. N. Synthesis of some New Derivatives of D-Mannose. Chittagong Univ. J. Sci. 2005, 29, 01-08.

21. Ichinari, M.; Nakayama, K.; Hayase, Y. Synthesis of 2,4-Dioxoimidazolidines from 2-arylimino-1,3-triazines and their Antifungal Activity. Heterocycles (Tokyo). 1988, 27, 26352641.

22. Gawande, N. G.; Shingare, M. S. Synthesis of Some Thiazolylthiosemicarbazides, Triazoles, Oxazoles, Thiadiazoles \& their Microbial Activity. Ind. J. Chem. 1987, 26, 387-389.

23. Gupta, R.; Paul, S.; Gupta, A. K.; Kachroo, P. L.; Bani, S. Synthesis and Biological Activities of Some 2-Substituted Phenyl-3-(3-alkyl/aryl-5,6-dihydro-s-triazolo[3,4-b][1,3,4]thiazolo-6-yl)-indoles. Ind. J. Chem. 1997, 36, 707-710.

24. Singh, H.; Shukla, K. N.; Dwivedi, R.; Yadav, L. D. S. Clycloaddition of 4-Amino3-mercepto-1,2,4-triazole to Heterocumulenes and Antifungal Activity of the Resulting 1,2,4-Triazolo[3,4-c]-1,2-dithia-4,5-diazines. J. Agric. Food Chem. 1990, 38, 1483-6.

25. Kabir, A. K. M. S.; Matin, M. M.; Kawsar, S. M. A. Synthesis and Antibacterial Activities of Some Uridine Derivatives. Chittagong Univ. J. Sci. 1998, 22, 13-8.

26. Kawsar, S. M. A.; Kabir, A. K. M. S.; Manik, M. M.; Hossain, M. K.; Anwar, M. N. Antibacterial and Mycelial Growth Inhibition of Some Acylated Derivatives of D-Glucopyranoside. Int. J. Biosci. 2012, 2, 66-73. 
27. Kabir, A. K. M. S.; Kawsar, S. M. A.; Bhuiyan, M. M. R.; Islam, M. R.; Rahman, M. S. Biological Evaluation of Some Mannopyranoside Derivatives. Bull. Pure Appl. Sci. 2004, 23, 83-91.

28. Kawsar, S. M. A.; Faruk, M. O.; Rahman, M. S.; Fujii, Y.; Ozeki, Y. Regioselective Synthesis, Characterization and Antimicrobial Activities of Some New Monosaccharide Derivatives. Sci. Pharm. 2014, 82, 1-20.

29. Kawsar, S. M. A.; Sharif, U.; Manchur, M. A.; Fujii, Y.; Ozeki, Y. Acylation of D-Glucose Derivatives Over $\mathrm{C}_{5} \mathrm{H}_{5} \mathrm{~N}$ : Spectral Characterization and In Vitro Antibacterial Activities. Int. J. Biol. Chem. 2015, 9, 269-282.

30. Bauer, A. W.; Kirby, W. M. M.; Sherris, J. C.; Turck, M. Antibiotic Susceptibility Testing by a Standardized Single Disc Method. American J. Clin. Pathol. 1966, 45, 439-476.

31. Miah, M. A. T.; Ahmed, H. U.; Sharma, N. R.; Ali, A.; Miah, S. A. Antifungal Activity of Some Plant Extracts. Bang. J. Bot. 1990, 19, 05-10.

32. Grover, R. K.; Moore, J. D. Toximetric Studies of Fungicides Against the Brown Rot Organisms Sclerotinia flucticola and S. laxa. Phytopathology. 1962, 52, 876-880.

33. Kabir, A. K. M. S; Matin, M. M; Kawsar, S. M. A. Selective Acylation of Uridine Using the Dibutyltin Oxide and Direct Methods. Chittagong Univ. Stud. Part-II: Sci. 1997, 21, 39-45.

34. Kawsar, S. M. A.; Nishat, S. S. B. S.; Manchur, M. A.; Ozeki, Y. Benzenesulfonylation of Methyl $\alpha$-D-Glucopyranoside: Synthesis, Characterization and Antibacterial Screening. Int. Lett. Chem. Phys. Astron. 2016, 64, 95-105.

35. Kawsar, S. M. A.; Hamida, A. A.; Sheikh, A. U.; Hossain, M. K.; Shagir, A. C.; Sanaullah, A. F. M.; et al. Chemically Modified Uridine Molecules Incorporating Acyl Residues to Enhance Antibacterial and Cytotoxic Activities. Int. J. Org. Chem. 2015, 5, 232-245. 